\title{
An Examination of the Differential Impact of Regulation FD on Analysts' Forecast Accuracy
}

\author{
A Thesis Submitted to the College of \\ Graduate Studies and Research in \\ Partial Fulfillment of the Requirements \\ for the Degree of Masters of Science in Finance \\ in the Department of Finance and Management Science \\ University of Saskatchewan \\ Saskatoon, Saskatchewan
}

Scott B Findlay

CCopyright Scott B Findlay, April 2003. All rights reserved 


\section{Permission To Use}

In presenting this thesis in partial fulfillment of the requirements for a Postgraduate degree from the University of Saskatchewan, I agree that the Libraries of the University of Saskatchewan may make it freely available for use in both print and

electronic form. I further agree that permission for copying of this thesis in any manner, in whole or in part, for scholarly purposes may be granted by the professor who supervised my thesis work or, in his absence, by the Head of the Department or the Dean of the College of Commerce. It is understood that any copying, publication, or use of this thesis (or parts thereof) for financial gain will not be allowed without my personal written permission. It is as well understood that due recognition shall be given to myself and the University of Saskatchewan in any scholarly use which may be made of any materials in this thesis.

Requests for permission to copy or to make other use of materials found in this thesis in whole or in part should be addressed to:

Head of the Department of Finance and Management Science

College of Commerce

University of Saskatchewan

25 Campus Drive

Saskatoon, Saskatchewan

S7N $5 A 7$ 


\begin{abstract}
The stated intent of Regulation FD was to create a level playing field between all market participants by requiring publicly traded companies to widely and publicly disseminate all material information. By restricting selective pre-earnings announcement guidance to analysts, there is now equal access to company-specific information not only between the general investing public and analysts but also between competing analysts. I examine the differential impact of the regulation on the forecast accuracy of superior, average, and inferior analysts. I find that the forecast accuracy has declined for each group and that on a relative basis, inferior (superior) analysts performance has improved (deteriorated) subsequent to the implementation of Regulation FD. My findings suggest that selective guidance provides some explanation for the differential forecasting ability of analysts prior to the implementation of Regulation FD.
\end{abstract}

I also examine the impact of Regulation FD on the ability of a model to forecast which analysts will be the most accurate with their earnings forecast estimates. I find that since Regulation FD has been implemented these models have increased their ability to predict which analysts will make the most accurate forecasts. 


\section{Acknowledgements}

I would like to express my sincere gratitude to my thesis supervisor Dr. Prem Mathew. His continued support, guidance, and constructive comments made my work on this thesis rewarding and enjoyable. It has been my great pleasure to have the opportunity and privilege to have worked with him. I would as well like to thank the other members of my thesis committee, Dr. Dale Domian and Dr. Marie Racine. Their suggestions and pointers during this process have allowed me to explore the research on my topic in a constructive manner.

I gratefully acknowledge the contribution of Thomson Financial for providing earnings per share forecast data, available through $\mathrm{I} / \mathrm{B} / \mathrm{E} / \mathrm{S}$. This data has been provided as part of a broad academic program to encourage earnings expectation research. Without the contribution of this data the research in this thesis would not have been possible. 


\section{Table of Contents}

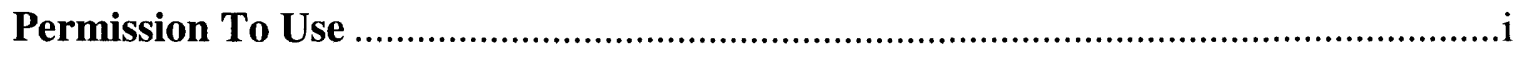

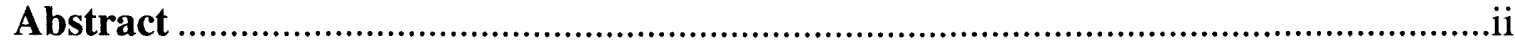

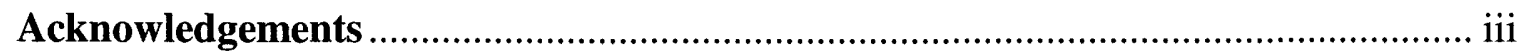

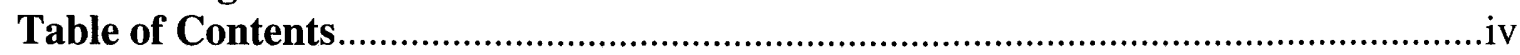

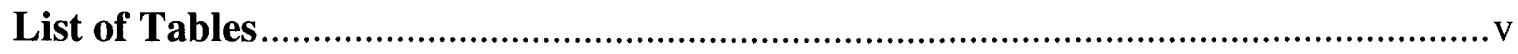

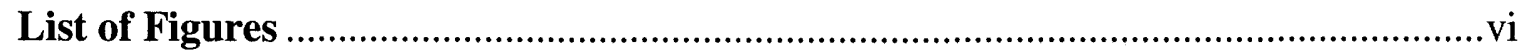

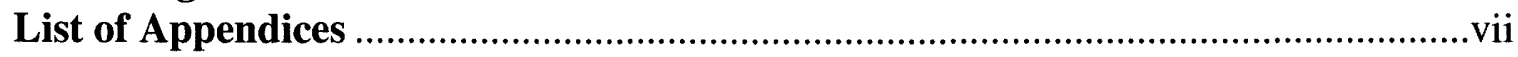

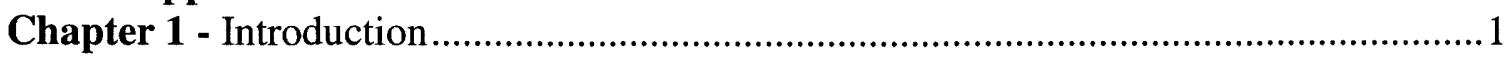

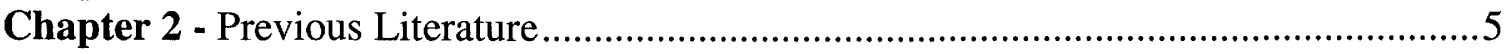

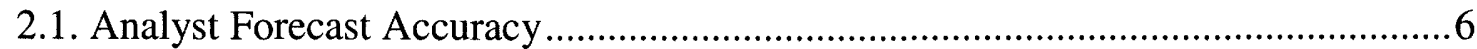

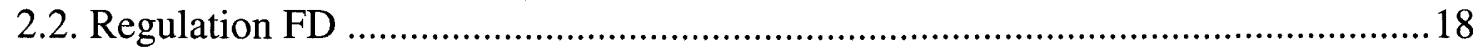

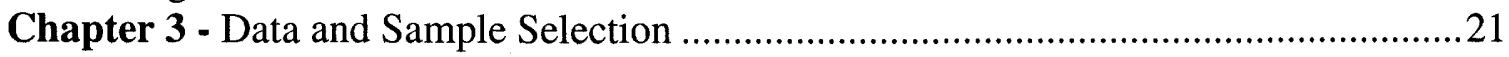

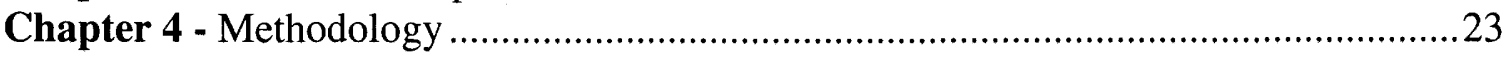

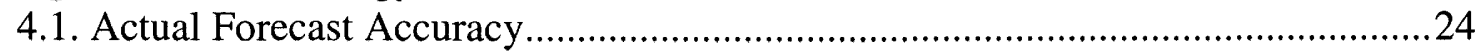

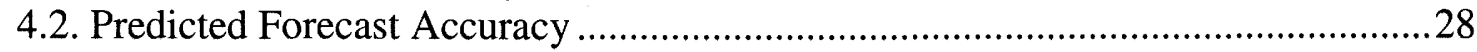

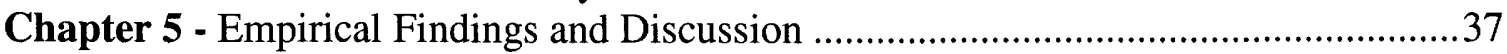

5.1. Effect of Regulation FD on actual relative and absolute forecast accuracy...........38

5.2. Effect of Regulation FD on superior, average and inferior analysts by industry ...42

5.3. Effect of Regulation FD on consistently superior, average and inferior analysts ..44

5.4. Determinants of Forecast Accuracy ............................................................ 48

5.5. Differential Predicted Forecast Accuracy .........................................................52

5.6. Effect of Regulation FD on Relative Forecast Accuracy for Model Classified

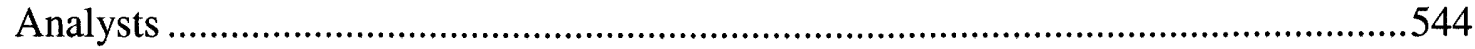

5.7. Effect of Regulation FD on Absolute Forecast Accuracy for Model Classified

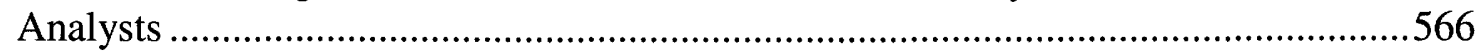

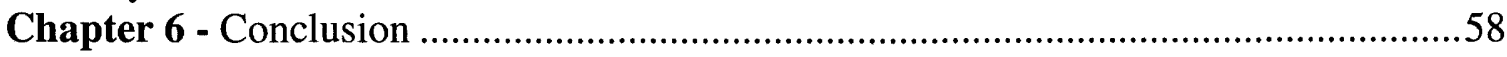

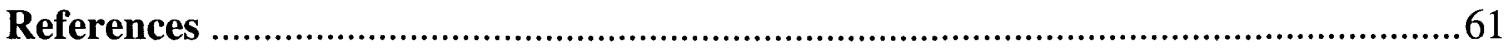




\section{List of Tables}

Table 1 - Summary Statistics.

Table 2 - Differences in relative and absolute forecast accuarcy for actual analyst groups in the pre- and post-FD periods

Table 3 - Differences in forecast accuracy for actual superior analysts by industry in the pre- and post-FD periods

Table 4 - Differences in forecast accuracy for actual inferior analysts by industry in the pre- and post-FD periods

Table 5 - Differences in forecast accuracy for actual average analysts by industry in the pre- and post-FD periods

Table 6 - Differences in forecast accuracy for consistently superior, average, and inferior analysts: Quarterly

Table 7 - Differences in forecast accuracy for consistently superior, average, and inferior analysts: Annual

Table 8 - Differences in absolute forecast accuracy between analyst groups during the pre- and post-FD periods

Table 9 - Regression results examining explanatory power of analyst-specific variables

- Model (1).

Table 10 - Regression results examining explanatory power of analyst-specific variables - Model (2)

Table 11 - Regression results examining explanatory power of analyst-specific variables - Model (3)

Table 12 - Correlation Matrix - Model (3)

Table 13 - Differences in realtive forecast accuracy for predicted superior and inferior analysts

Table 14 - Differences in realtive forecast accuracy for predicted superior and average analysts

Table 15 - Differences in realtive forecast accuracy for predicted average and inferior analysts

Table 16 - Regression results examining explanatory power of analyst-specific variables including an FD dummy variable.

Table 17 - Differences in relative forecast accuracy for predicted analyst groups in the pre- and post-FD periods

Table 18 - Differences in absolute forecast accuracy for predicted analyst groups in the pre- and post-FD periods 


\section{List of Figures}

Figure 1 - Chart of Differences in Absolute Forecast Accuracy over time .....................83 


\section{List of Appendices}

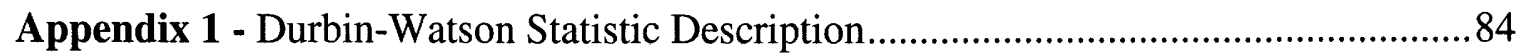

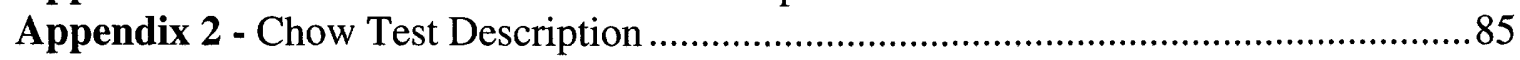




\section{Chapter 1}

\section{Introduction}

On October 23, 2000, the Securities and Exchange Commission (SEC), in the United States of America, put into effect Regulation Fair Disclosure (FD). The intent of this regulation was to eliminate the practice of selective disclosure by companies by requiring all material information, communicated by a company, to be widely and publicly disseminated. In the SEC's final rule document, they liken selective disclosure to insider trading, as only a privileged few (security analysts and institutional investors) are privy to these disclosures. The following colorful remark by former SEC Chairman Arthur Levitt speaks toward the concerns of the SEC: "[t]he behind-the-scenes feeding of information from companies to analysts is a stain on our markets."

By having voluntary disclosure practices fall under the scope of Regulation FD, and thus under the scrutiny of the SEC, the aim was to create a level playing field between all market participants regardless of their size or status. Regulation FD effectively eliminates the ability of selective disclosure recipients to take advantage of the acquired information prior to public dissemination of that information. The general consensus among security analysts about the impact of Regulation FD is that the quality and quantity of information being provided to them subsequent to the implementation of the regulation has deteriorated. Analysts contend that the same level of guidance provided to them about future earnings is no longer available since regulation FD has been implemented. Additionally, the informal information-gathering sessions between 
analysts and companies are no longer valuable. Surveys of analysts by the Securities Industry Association (SIA) and by the Association for Investment Management and Research (AIMR) indicate that the majority of analysts believe that there has been a significant deterioration in the quality of the oral communication. ${ }^{1}$

Regardless of the quality and quantity of information issued by firms subsequent to the adoption of Regulation FD, compliance with the regulation necessarily means that a level playing field has been created not only between the general investing community and analysts, but, more importantly for this study, also between analysts following a particular company. Although previous research provides us with an understanding of some of the determinants of analysts' earnings forecast accuracy, these studies were not able to separate the effects, of the analysts' inherent ability and the analysts' access to information, on forecast accuracy. In a study that examines the significance of firm-specific experience, Mikhail, Walther and Willis (1997, p. 132) concede this issue commenting that they "...cannot separate learning effects from the effects of improved access to management information as the analyst gains experience..". By comparing the pre- and post-Regulation FD environments it will allow researchers to now distinguish between the two effects. If analysts are not privy to selective pre-announcement guidance, it necessarily would follow that the analysts that perform relatively well (as compared to other analysts) must be doing so with

\footnotetext{
${ }^{1}$ The SIA survey conducted in May of 2001 finds that $72 \%$ of the surveyed analysts believe information communication has deteriorated post-Regulation FD (press release can be seen at http://www.sia.com/press/html/pr_chill_fd.html). The AIMR survey made public on October 18, 2001, of 303 AIMR members who responded in September, finds that $55 \%$ of those surveyed believe that the usefulness of oral communication has deteriorated. (complete results can be seen at http://www.aimr.com/pdf/01RegFDtable.pdf)
} 
fundamental research subsequent to Regulation FD. If an analyst outperforms his peers because of superior research or superior information interpretation skills, I would then expect that the same analyst would continue to perform well subsequent to Regulation FD. If, on the other hand, a significant portion of an analyst's superior performance can be attributed to the guidance provided by companies, I would then expect that subsequent to Regulation FD this analyst would not consistently outperform his peers.

A survey by PricewaterhouseCoopers of top executives provides anecdotal evidence of the perceived changes in analyst performance around Regulation FD. Surveyed executives believe that the "best" analysts are spending more time on fundamental research and that there are more pronounced differences between the "best" and "average" analysts following the implementation of the regulation. ${ }^{2}$

In this thesis, I re-examine analyst performance to determine whether analysts are able to generate quality forecasts of earnings because they are more adept at information interpretation and fundamental analysis, or because they are privy to selective disclosure.

I examine this issue in two ways. First, by partitioning my analyst sample into superior, average and inferior analysts based on pre-FD earnings forecast accuracy, I analyze the effects of the regulation on each of these classified groups. I find that all three groups generate less accurate forecasts subsequent to the Regulation FD implementation. However, I also find that the performance of superior analysts is relatively worse after Regulation FD compared to average and inferior analysts, and that

\footnotetext{
${ }^{2}$ PriceWaterhouseCoopers Management Barometer Survey of 101 CFOs interviewed in Q3 of 2001. Findings were reported on August 14, 2001 highlights of which can be found at http://www.barometersurveys.com/pr/mg010814.html
} 
inferior analysts perform relatively better. This suggests that at least a part of the explanation for the differential performance prior to the regulation is due to the fact that superior analysts were privy to selective guidance. Differences in forecast accuracy between the three analyst classifications are insignificant subsequent to Regulation FD (where as these differences were significant before), which suggests that a level playing field has been created between all analysts.

Secondly, I employ, from previous research (Clement, 1999 and Brown, 2001), an intuitively appealing analyst-specific model that is used to predict analysts' accuracy in forecasting earnings. I find that this model is better able to predict whether an analyst will be either superior or inferior subsequent to Regulation FD. This suggests that a variable that provided some explanatory power prior to the implementation of Regulation FD is no longer a factor. I suggest that this variable is the differential access to corporate guidance that used to exist between some analysts.

This thesis is organized as follows. Chapter 2 discusses previous literature related to forecast accuracy, and separately, the impact of Regulation FD on the financial information environment. Chapter 3 presents the data and sample selection for my thesis. Chapter 4 present the methodology employed. Chapter 5 presents the empirical finding and Chapter 6 concludes. 


\section{Chapter 2}

\section{Previous Literature}

This chapter reviews the relevant previous literature on analysts' earnings estimate accuracy and as the impact of Regulation FD. This chapter will discuss how each of the prior literature and research relate to each other. The chapter is organized as

follows: Section 1 reviews prior research as it relates to analysts' forecast accuracy; Section 2 reviews prior research on the impact of the implementation of Regulation FD. 


\subsection{Analyst Forecast Accuracy}

The widely-held opinion that some analysts are more accurate than others has only been empirically verified in academic research during the past ten years. Early research by Brown and Rozeff (1980), O'Brien (1990) and Butler and Lang (1991), using various methods and samples, concluded that there is no significant evidence of differential forecasting ability amongst analysts based on the findings in their respective samples. One common drawback of each of these studies, however, is that there is either no control, or an insufficiently powerful control, for the age of the analysts' earnings forecast. Brown, Richardson and Schwager (1987), O'Brien (1988) and Kross, Ro, and Schroeder (1990) show that forecast age is a key determinant of an analyst's earnings forecast accuracy. Therefore, models that do not explicitly control for forecast age could lead to inconclusive or misleading results, as these earlier studies did.

Brown, Richardson and Schwager (1987) compare error variances to see if financial analysts' earnings forecasts (FAF) are superior to earnings forecasts made by a model. Brown et al. (1987) compare the variance of random walk forecast errors to the variance of FAF errors and believe this will reflect the analysts' forecasting superiority. The definition of superiority used in their research is:

$$
F A F S U P=\frac{\sigma^{2}{ }_{R W}}{\sigma^{2}{ }_{F A F}}
$$

Where:

$$
\begin{aligned}
& \sigma^{2}{ }_{R W}=\text { variance of random walk forecast error } \\
& \sigma^{2}{ }_{F A F}=\text { variance of financial analyst forecast error }
\end{aligned}
$$

Brown et al. find that even after controlling for differentiating factors such as forecast age, industry, and forecast horizon that FAF superiority is significant and that it is positively related to firm size and negatively related to previous forecast dispersion. 
They also find that the control variables provide significant explanatory power to the accuracy of the FAF. The control variables for forecast age and forecast horizon (how many quarters out the estimate is for) are found to be negatively related to forecast accuracy.

Kross, Ro and Schroeder (1990) examine the analyst advantage by extending the work of Brown et. al (1987) to include variables that indicate the extent of firm coverage in the Wall Street Journal Index and past earnings variability of the firm. Kross et al. believe that the amount of coverage in the Wall Street Journal Index can be seen as a proxy for the amount of information about the company that is available in the public marketplace. They find that the past earnings variability and the amount of coverage is positively related to the analyst advantage. They conclude that analysts will spend their research time on companies with high past earnings variability, as this is where the analysts efforts on research will be able to make more of a difference (from a model). The less (more) powerful the past earnings are as a predictor of future earnings the more (less) difference an analyst can make in differentiating his earnings estimates from a time-series estimate. Kross et al. (1990), however, do not find that firm size is a significant explanatory factor (where as Brown et al. (1987) do) and do not believe that firm size should be used as a control variable.

Kross et. al (1990) also use a significantly different definition of analyst advantage from that used by Brown et. al (1987). Kross et al. (1990) defines the analyst advantage $(A A)$ as the difference between the absolute value of the forecast error for the time series model $\left(E F E_{T S}\right)$ and the absolute value of the forecast error of the Value Line $\left(E F E_{\mathrm{VL}}\right)$ estimates (which they use to represent the analysts' earnings forecasts). In this 
case, a positive (negative) value for the AA would indicate that analysts were more (less) accurate than a time series model. The definition of analysts' advantage (AA) used by Kross et al. (1990) is:

$$
A A=\left[\left|E F E_{T S}\right|-\left|E F E_{V L}\right|\right]
$$

Kross et al. (1990) use a univariate time series model which was originally suggested by Brown and Rozeff (BR) $(1979)^{3}$. Kross et al. (1990) show that there are certain determinants which will allow us to predict which securities analysts' earnings forecasts will be more accurate than a time series model forecasts. Kross et al. (1990) agree with Brown et al. (1987) that in order to compare analysts' earnings estimates researchers must control for some variables to get true generalizable results. These variables are the time variable and the industry variable.

Both of these studies, using various methods, find that analysts, as a group, outperform naïve models of earnings forecasts. These studies, however, do not examine whether there are differences between individual analysts with regards to their ability to accurately forecast earnings.

Stickel (1992) provides us with initial insight into the differences in forecasting ability between analysts. He analyzes the performance of analysts who are part of the Institutional Investor (II) All-American Research Team (AART) versus non-AART analysts. Each October, II places analysts on its AART based on information from about 2,000 money managers. Money managers place analysts on the AART team basing their evaluation of each analyst on ten categories. In descending order of importance the categories are: industry knowledge; special services (which include

\footnotetext{
${ }^{3}$ For a more detailed explanation of the model used please see Krosse et al. (1990) and Brown and Rozeff (1979)
} 
company visits and roadshows); financial models; written reports; earnings estimates; servicing; stock selection; quality of sales force; market making; and primary market services. Using a matched-pair design (by firm and forecast age), Stickel (1992) finds strong evidence that AART members are more accurate than non-AART members. $\mathrm{He}$ also finds that AART members revise their forecasts more frequently than non-AART members. Because the method measures forecast accuracy differential between AART and non-AART members, the generalizability of his findings may be limited as AART members are not primarily evaluated on their earnings forecast precision. Additionally, the matched-pair design, where an exact estimate date match is required, results in a loss of $88 \%$ of the original sample.

Despite its limitations, Stickel's (1992) seminal work shows that there are, in fact, differences in analysts' forecast accuracy. This result provided a stepping-stone for subsequent research with the focus shifting to other possible analyst characteristics (other than if an analyst is on the AART) that could help to explain differences in the analyst's ability to forecast earnings.

Sinha, Brown, and Das (1997) extend the understanding of differential analyst ability by using a predictive framework to determine whether there is persistence in analysts' relative performance. Sinha et al. (1997) classify each individual analyst as a separate independent variable. They then compare the accuracy of the analyst's earnings forecast to that of a randomly selected analyst who made an earnings estimate within \pm 5 days for the same firm. Sinha et al. (1997) then run a regression to see if any analyst specific variables are found to be significant in predicting estimate accuracy (which would lead us to conclude that certain analysts are more accurate than others). 
Sinha et al. (1997) find that there is strong evidence that certain analysts are in fact more accurate than others.

Sinha et al. (1997) then take their results and see if they persist in an ex ante analysis (out of sample). They test this by ranking analysts as either superior or inferior based on the analyst's absolute earnings forecast error during a pre-set time period. Then these "superior" ("inferior") classified analysts are matched up with an average analyst and their absolute percentage earnings forecast errors were compared. Again the matching is done based on the closest average analyst with an earnings estimate for the same firm whose earnings estimate was made within \pm 5 trading days. If no average analyst is found then the observation was dropped. The comparison is done based on whether the analyst was defined as superior or inferior in the estimation period; however, the values for the percentage earnings forecast error comparison come from a holdout (ex ante) period. This allows Sinha et al. (1997) to test for the persistence of superiority or inferiority by analysts over time. The ranking of the analysts as either superior or inferior is done for periods of $1,2,3$, and 4 years. In order for an analyst to be considered superior or inferior in the holdout period an analyst has to be ranked as superior or inferior for each year within the classification time period. For the $1(2,3,4)$ year period the analyst is ranked as superior if his absolute forecast error is less than the $25^{\text {th }}\left(33^{\text {rd }}, 50^{\text {th }}, 50^{\text {th }}\right)$ percentile of the distribution of all the analysts' forecast errors for that firm. If the absolute forecast error is greater than the $75^{\text {th }}\left(66^{\text {th }}, 50^{\text {th }}, 50^{\text {th }}\right)$ percentile the analyst was ranked as inferior.

Overall, Sinha et al. (1997) find that there is strong evidence that analysts ranked as superior in one period will remain superior in the next (especially when 
ranking analysts using a 1 year time period). When looking at analysts who are ranked as inferior there is some evidence of persistence but much less (primarily just persistent when using the 1 year time period definition of inferior) and it does not seem to suggest an inferior analyst will remain an inferior analyst over time.

This paper by Sinha et al. (1997) does lead me to believe that there are differences in the earnings estimate accuracy of analysts that are sustainable over time. Sinha et al. (1997) also provide proof that the recency of analysts' earnings forecasts must be accounted for in tests of earnings forecast accuracy, otherwise the recency effect may hide the real results that are being sought.

Given that superior analysts appear to persistently perform well, the next obvious question is what characteristics enable these analysts to do so? Clement (1999) examines various analyst-specific characteristics that can be useful in determining whether an analyst's estimates will be either superior or inferior. Clement (1999) analyzes the "learning-by-doing" effect on forecast accuracy by examining an analyst in terms of general experience (years that an analyst has been active) and companyspecific experience (years an analyst has been following a specific company). He also looks at the size of the brokerage firm where the analyst works (which he believes is a proxy for the resources available to the analyst), and the number of firms and industries an analyst follows (which are proxies for the complexity of the analyst's job).

One of the unique contributions made by Clement is the definition of the dependent variable which he uses to represent the accuracy of the analyst's earnings estimates:

$$
P M A F E_{i j t}=\frac{D A F E_{i j t}}{\overline{A F E_{j t}}}
$$


Where:

$$
D A F E_{i j t}=A F E_{i j t}-\overline{A F E_{j t}}
$$

Where:

$A F E_{i j t}=$ Absolute forecast error for analysts $i$ 's forecast for firm $j$ for year $t$.

$\overline{A F E_{j t}}=$ Mean absolute forecast error for all analysts following firm $j$ for year $t$.

$P M A F E_{i j t}=$ Proportional mean absolute forecast error for analyst $i$, for stock $j$, for year $t$.

By deflating $D A F E$ by $\overline{A F E}$, it reduces heteroscedacity and it controls for firmspecific effects (which may make it harder to estimate earnings for a specific firm) and year-specific effects (which may make it harder to have accurate earnings estimates in one year than in another). Any firm or year effect that effects analyst $i$, will, as well, affect all analysts and therefore, the mean forecast error $(\overline{A F E})$ will be adjusted as well as the analyst forecast error $(A F E)$. Therefore, these net effects will cancel each other out. This allows Clement (1999) to compare earnings forecast performance measure $(P M A F E)$ across years or firms without worrying about the effect of firm or year effects.

One of the differences introduced by imposing this definition of analysts' earnings forecast accuracy (PMAFE) (from definitions used by other researchers previously) is that it can come up with negative numbers. Since I am subtracting the average error and then scaling by the average error, an analyst who has a perfect estimate (the analyst's earnings estimate is exactly the true earnings) will end up with a $P M A F E$ of -1.00 . In fact, any PMAFE which has a negative (positive) value means that the particular analyst is more (less) accurate than average. The larger the positive number the relatively less accurate the particular analyst is. In this model, any 
independent variable that has a negative relation to the dependant variable actually contributes to the relative accuracy of the analyst, while any independent variable with a positive relation to the dependant variable reduces the relative accuracy of the analysts' earnings estimates.

Clement (1999) does control for the age of the analysts earnings estimates by introducing an age variable, which is defined as the number of days from when the estimate was made until the year end. This age control variable allows him to compare earnings estimates which were made on different dates amongst the analysts. Clement (1999) does find that the age variable is a significant control variable which, if not considered, would hide a lot of the other findings.

Clement (1999) finds that an analyst's earnings forecast accuracy is positively related to both general and company-specific experience, positively related to brokerage house size, and negatively related to both number of industries and number of companies followed by the analyst. These findings are intuitively appealing as the more experience an analyst has (as measured by general and company specific) the more accurate I would expect him to be since he is better able to determine what information is relevant and how it will affect the firm. The larger the brokerage house for which the analyst works the more resources he should have available to him (in terms of research assistants and company contacts) so the more accurate I would expect him to be. The larger the number of companies the analyst follows the less time the analyst will have for research and analysis of each company and the less accurate his estimates would likely be. The larger the number of industries the analyst follows the greater the breadth of information required by the analyst. Therefore more overall research time will be 
needed and since research time is a finite resource the less accurate I would expect the analyst's estimates to be.

Brown (2001) extends the analysis on differential forecasting ability by examining the predictive power of the model proposed by Clement (1999). To accomplish this, Brown (2001) runs yearly regressions of the model originally put forward by Clement (1999). Brown (2001) uses the regression coefficients from this model (based on the past year's data) and the actual explanatory variable values (for the present year's data) to predict the relative accuracy of an analyst for the next year. Based on these predictions of accuracy, analysts are partitioned into deciles. Brown (2001) then compares the actual accuracy of the predicted best performing decile to that of the predicted worst performing decile. He shows that the predicted top analysts are more accurate (up to $32 \%$ more accurate) than the average analysts. Additionally, the predicted bottom analysts are less accurate than average (up to $95 \%$ less accurate). This indicates that this model can be used in predicting the relatively accuracy of analysts in ex ante periods.

Concurrent to the work by Clement (1999), Jacob, Lys, and Neale (1999) examine how analyst-specific characteristics and the environment within a brokerage house affects the forecast accuracy of analysts. Jacob et al. (1999) test to see if 5 different attributes of a brokerage house affect the accuracy of the earnings estimates of analysts who work at these particular brokerage houses. The attributes tested were:

1) If there has been a change in the analyst making the earnings estimate for the brokerage house during the period.

2) The frequency with which the analyst makes earnings estimate revisions. 
3) The percentage of analysts in the brokerage house, for which the analyst works, who follow the same industry that this earnings estimate is for. This is seen to be a proxy for the degree of industry specialization of the brokerage house.

4) The percentage of new analysts coming into the brokerage house relative to the total number of analysts working for that brokerage house.

5) The percentage of analysts who left the brokerage house relative to the total number of analysts working for that brokerage house.

Jacob et al. (1999) find that the frequency of analyst earnings revisions and the degree of industry specialization are positively related to the analysts' earnings forecast accuracy while the percentage of analysts who left the house is negatively related to earnings forecast accuracy.

Jacob et al. (1999) also find that the analyst's innate ability is a significant explanatory variable of an analyst's earnings forecast accuracy. However, they find that when controlling for company-specific aptitude, the experience variable (both company specific experience and general experience), found to be significant by Clement (1999) and Mikhail, Walther and Willis (1997), is no longer found to be significant.

Brown and Mohammad (2001) try to determine the "economic significance" of being able to better predict individual analyst's earnings forecast accuracy. In their study, they try to determine how to make a weighted earnings consensus, from analysts' estimates, which is more accurate than just the means weighted earnings estimate. In order to test their theory, they employ a six variable model to estimate analysts' earnings accuracy, and then run a Least Squares regression on this model for each year. 
They use the variable estimates from this model in order to forecast which analysts will be the most accurate for the next period. The six variables they use in their model are:

1) The forecast age of the estimate.

2) The firm specific experience of the analyst.

3) The number of firms that the analyst follows.

4) The number of industries that the analyst follows.

5) The size of the brokerage house for which the analyst works.

6) The forecast frequency of the analyst.

They use, as previous researchers have, the last earnings estimate made by an analyst and only include companies that have at least five analysts following them. Using the variable estimates from the regression they then make four different consensus earnings estimates for the next time period. The four different consensus earnings estimates are:

1) Means Estimate - The mean average of all of the analysts' estimates.

2) Age Estimate - An estimate where the analyst weighting is determined on the basis of a model which only includes the age control variable.

3) Model Estimate - An estimate where the analyst weighting is determined on the basis of the six factor model. The analysts determined to be the most accurate based on the model estimates is given the most weight.

4) Perfect Estimate - An estimate where the analyst weighting is based on an after the fact knowledge of which analysts were in fact the most accurate.

Brown and Mohammad (2001) then use a sum-of-the-years weighting system to come up with their new consensus analyst earnings estimates. This is where the 
analysts predicted to be the most accurate gets a weighting of $N /\left[N^{*}(N+1)\right] / 2$, and the analyst predicted to be the least accurate gets a $1 /\left[N^{*}(N+1)\right] / 2$ weighting, where $N$ equals the number of analysts.

Brown and Mohammad (2001) then use a trading rule where if the estimate for any of the model consensus estimates is $5 \%$ greater (less) than the means consensus estimate they buy (short) the stock and hold it for a 30 day period. The abnormal return for each of these trading models is then compared.

Brown and Mohammad (2001) find that following the buy trading strategy brings about excess returns for the model estimate portfolio which is significantly above the means consensus returns; however the shorting trading strategy (for the model estimate portfolio) does not produce abnormal returns. The return for the age portfolio is not found to be significantly greater than that of the means estimate. Brown and Mohammad (2001) also find that the model estimate portfolio still only gives you about $40 \%$ of the perfect model's return. This points to the fact that there is still a lot of room for improvement in the model, and that any improvement in the model which would help to create a better consensus earnings estimate could lead to an opportunity to capture some abnormal returns. 


\subsection{Regulation FD}

The majority of the currently available literature on the impact of Regulation FD has focused on the effect of the regulation on information flows into the financial market. Heflin, Subramanyam and Zhang (2001) examine abnormal return volatility around earnings announcements and find that there is actually lower return volatility subsequent to the implementation of the regulation. They conclude from this that there has been no deterioration of information flow post-Regulation FD. They also analyze the extent to which consensus analysts' forecast characteristics change subsequent to Regulation FD. They find no significant evidence that Regulation FD has had a negative effect on analysts' earnings forecast bias, accuracy or dispersion. They conclude that although information communication to analysts is now limited, the performance of analysts has not deteriorated.

Heflin et al. (2001) do find that since the implementation of Regulation FD that there has been an increase in the amount of voluntary information disclosures by companies. They believe that analysts may be using the information included in these disclosures as at least a partial substitute for the private information they were getting before, and this may be part of the reason that the analyst's earnings estimate accuracy has not suffered. Heflin et al. (2001) do not attempt to examine the differential impact of the regulation on different subsets of analysts as is done in this thesis.

In a study most closely related to this thesis, Mohanram and Sunder (2002) analyze the differential impact of Regulation FD on the performance of AART analysts and non-AART analysts. Unlike Heflin et al. (2001), they find that analysts as a group have been adversely affected by the implementation of Regulation FD as both forecast 
error and forecast dispersion have significantly increased. However, the impact is not uniform across all analysts. They categorize AART analysts as superior and find that although AART analysts are adversely affected by the regulation it is not to the same extent as non-AART analysts. Therefore, they conclude that the accuracy gap between the two groups has increased post-FD.

There are a number of deficiencies with the methodology used by Mohanram and Sunder (2002) that are addressed in this thesis. First, classifying AART analysts as superior analysts for the purpose of earnings forecast accuracy measurement is somewhat inaccurate. As discussed earlier, earnings estimate accuracy is only the fifth most important category in the AART classification. Therefore it may not necessarily be the case that AART analysts are in fact the most accurate earnings forecasters. Secondly, the study does not incorporate analyst-specific variables in their model. When determining the accuracy of an analyst's forecast, it seems reasonable that one would examine and control for analyst-specific characteristics as in Clement (1999) and Brown (2001) rather than the firm-specific controls used. Thirdly, Mohanram and Sunder (2002) do not incorporate a control variable for the forecast age. When comparing AART and non-AART analysts, Stickel (1992) used a matched-pair design that accounted for forecast age. Given that a number of previous studies have found forecast age to be a key determinant in forecast accuracy, the reliability of Mohanram and Sunder's (2002) findings are questionable.

This thesis examines the issue of changes in differential forecasting ability in a more comprehensive nature as described in a subsequent section. By doing this it 
addresses some of the problems mentioned above enabling me to focus specifically on forecast accuracy. The results are therefore more generalizable. 


\section{Chapter 3}

\section{Data and sample selection}

The data for this thesis is from the $\mathrm{I} / \mathrm{B} / \mathrm{E} / \mathrm{S}$ International, US Edition Academic Version, detailed historical database. This database includes quarterly and annual earnings estimates for more than 300 brokerage houses and 3,000 individual analysts for the time period from 1982 to 2001. Analyst-specific information includes brokerage house affiliation and all earnings estimates for a particular stock for a particular period.

Consistent with prior research, the last forecast made by each analyst for each period for each firm is used. ${ }^{4}$ As more recent estimates would necessarily incorporate all prior information plus any new information since a previous estimate, this would be seen as being an analyst's "best guess" as to what the actual earnings will be. This selection also avoids the issue that analysts with more frequent revisions would have a greater representation in the data set and hence a greater influence on the results.

The sample is further reduced based on the following factors. Observations where the analyst code is zero are removed. This is the $\mathrm{I} / \mathrm{B} / \mathrm{E} / \mathrm{S}$ representation for an analyst who wishes to remain anonymous. Because there is no way to follow any particular analyst's history or accuracy (if they remain anonymous) they do not add anything to the research in this thesis. Observations where the date of the estimate is subsequent to the announcement period are removed. This is believed to represent erroneous observations. Observations where there is no actual earnings information

\footnotetext{
${ }^{4}$ Clement (1999), O'Brien (1990), Mikhail, Walther and Willis (1997), and Brown and Mohammad (2002) all employ this method.
} 
available are removed. Observations where the measure of the analyst when reporting a company's earnings does not match the measure reported for the actual earnings are removed. Since all of the actual earnings are reported as Earnings per Share (EPS) ${ }^{5}$, any other type of estimate is removed. The most common other type of earnings announcement was Cash Earnings per Share (CEPS). Without knowing what the analyst did or did not include in their estimate, I cannot reconcile their CEPS numbers with the EPS numbers. Since many of the tests include relative measures of accuracy, companies that are only followed by a few analysts each year (each quarter for the quarterly analysis) would not provide meaningful results, therefore I eliminate all firmyears (firm-quarters) in which the number of analysts covering a particular firm in a particular period is less than 5. All analysts that are in the database in 1983 are removed because of the inability to calculate general and firm-specific experience for these analysts ${ }^{6}$. For the quarterly analysis, I limit the sample to firms that have quarterends of March, June, September and December, which represent the majority of the entire sample. I also only use data from June 1993 onwards, for quarterly analysis, as this provides me with a sufficient sample size and $\mathrm{I} / \mathrm{B} / \mathrm{E} / \mathrm{S}$ states that data from June 1993 on is more reliable. Final sample summary statistics for the analyses are presented in Table 1.

\footnotetext{
${ }^{5}$ One of the issues with the data used in this research, that must be recognized, is that the estimates each individual analyst includes in their EPS estimates may not be identical to what other analysts include or to what is included in the numbers the company reports as their actual EPS. This is due to differences in what each analyst believes is appropriate (and what the company accountants believe) to be included. This issue does mean that comparing EPS estimates between analysts may be a little misleading as to which analyst is the most accurate. These differences though should be small in size and should not greatly affect the results which are found or the conclusions reached based on these results.

${ }^{6}$ This issue is elaborated on in the methodology section.
} 


\section{Chapter 4}

\section{Methodology}

The methodology used in this thesis is examined in this chapter. Section 1 looks at the methodology used when looking at the actual forecast accuracy of analysts earnings estimates. Section 2 looks at the methodology used when looking at the predicted forecast accuracy of analysts. 


\subsection{Actual Forecast Accuracy}

The first area that I want to examine in this thesis is whether specific analysts that were most (least) accurate prior to Regulation FD have remained so after the regulation was implemented. To accomplish this, I select analyst earnings forecast estimates for the most recent twelve months immediately prior to the implementation date (October 1999 to September 2000) and partition this sample into superior, average and inferior analysts where the top $10 \%$ (in relative forecast accuracy) represents the superior analysts and the bottom $10 \%$ represents the inferior analysts. I then match this sample by finding the same analyst covering the same firm in the twelve months immediately after Regulation FD went into effect. If an analyst no longer has an earnings estimate for that particular firm, the observation is dropped from the sample set. I then calculate the differences in relative accuracy (compared to other analysts following the same firm) of each of the three analyst groups and also the differences in absolute forecast accuracy for each of the three groups between the pre- and post-FD periods. This allows me to examine the relative and absolute effect of Regulation FD on the different categories of analysts. The definition of relative forecast accuracy I use is the definition used by Clement (1999) of PMAFE which is again defined as:

$$
P M A F E_{i j t}=\frac{A F E_{i j t}-\overline{A F E_{j t}}}{\overline{A F E_{j t}}}
$$

Where:

$A F E_{i j t}=$ Absolute forecast error for analysts $i$ 's forecast for firm $j$ for year $t$.

$\overline{A F E_{j t}}=$ Mean absolute forecast error for all analysts following firm $j$ for year $t$. 
$P M A F E_{i j t}=$ Proportional mean absolute forecast error for analyst $i$, for stock $j$, for year $t$.

Subtracting the mean forecast error and dividing by the mean forecast error for each firm-year allows us to compare across companies, analysts, and times ${ }^{7}$. Clement (1999) shows that deflating the analyst's differential forecast error by the mean forecast error reduces heteroskedasticity. Another advantage of using PMAFE is that it will allow me to verify that my results are consistent with what has been found in prior research.

I extend the testing of analysts' earnings forecast accuracy by breaking down the comparison of analysts on the basis of the industries for which they make their earnings estimates. I run the same comparative tests of PMAFE and AFE for superior/average/inferior analysts on the basis of each of the 11 industry classifications. ${ }^{8}$ I again compare the differences in relative and absolute forecast accuracy between the pre- and post-FD periods. This will allow me to test to see if analysts' earnings estimates for different industries are affected in different ways/levels by the implementation of Regulation FD.

To ensure that the results obtained in the above overall tests are not spurious findings, I perform the same analysis on analysts that have consistently outperformed (underperformed) their peers prior to Regulation FD. Using quarterly earnings forecasts,

\footnotetext{
${ }^{7}$ Jacob, Lys and Neale (1999) show that changes in economic conditions can affect forecast difficulty therefore a measure not deflated by mean forecast error would limit cross-year, and cross-company comparisons.

${ }^{8}$ I use the classification of a firm into an industry based on the two digit SIG code assigned to each firm.
} 
I define a superior (inferior) analyst as one who is in the top (bottom) quartile ${ }^{9}$ in each of the four quarters immediately prior to Regulation FD (Q4 1999, Q1-Q3 2000). I then compare the performance of the analyst during this pre-FD period to his performance in Q4 2000 and Q1 2001, the two quarters immediately after the implementation of the regulation. I calculate differences in both relative and absolute performance of these analysts. An analyst must have earnings forecasts documented for all six quarters to be included in the sample.

Since the sample size is dramatically reduced by the restrictions placed by this methodology, I re-examine this issue with the following two less restrictive pre-FD analyst categorizations. Firstly, rather than define superior (inferior) analysts based on four consistent quarters, I use two consistent quarters to select superior (inferior) analysts. Secondly, using annual earnings forecasts (instead of quarterly), I define superior (inferior) analysts as analysts that have outperformed (underperformed) their peers in each of the two years immediately prior to Regulation FD. I then compare, in relative and absolute terms, their performance prior to the implementation of Regulation FD to a post-FD period of one year (two quarters for the quarterly analysis).

Finally, I examine differences, in absolute forecasting accuracy subsequent to Regulation FD, between analysts that are classified as consistently superior, average or inferior in the pre-FD period. I compare the accuracy of superior classified analysts to the accuracy of average and inferior analysts to see if the levels of accuracy are different. I analyze the differences in both quarterly and annual forecast accuracy, classifying

\footnotetext{
${ }^{9}$ I use quartiles instead of deciles in this analysis because of the significantly smaller sample sizes found when using quarterly data and the restriction of having to be consistently superior (inferior).
} 
analysts as superior/average/inferior if their forecast accuracy in the two years (quarters) prior to the implementation of the regulation was in the top quartile/middle 50 percent /bottom quartile in each of the two years (quarters). The post-FD period is defined as the year (two quarters) immediately following Regulation FD for the annual (quarterly) forecast accuracy analysis. If the differences in accuracy between the classified groups are insignificant, I would conclude that the implementation of Regulation FD has created a level playing field between analysts (no analyst has a consistent advantage over other analysts). Persistent differences between the groups would suggest that there still is not a level playing field among analysts. 


\subsection{Predicted Forecast Accuracy}

The models that I use in this part of the study are presented in equation (1), (2), and (3). These models incorporate analyst-specific explanatory variables to estimate analyst relative forecast accuracy. These models are primarily based on Clement's (1999) model. The study that first suggests each of the explanatory variables is presented in parentheses immediately following the variable name. In this thesis, I evaluate these models to determine whether there has been a change in the predictive power of this model subsequent to the implementation of Regulation FD ${ }^{10}$.

Model 1 uses the variables defined previously as determinants of forecast accuracy. As Brown (2001) has shown, a model with just lagged forecast accuracy variable and a forecast age variable provides the same explanatory power as model (1) so this is represented in model (2). The third model (3) combines the two previous models and adds the additional explanatory variables of brokerage house size and frequency of estimates.

$$
\begin{aligned}
& P M A F E_{i j t}=a_{0}+a_{1} D A G E_{i j t}+a_{2} D G E X P_{i j t}+a_{3} D C E X P_{i j t}+a_{4} D N C O S_{i j t} \\
& +a_{5} D N S I G_{i j t}+\mu_{i j t} \\
& P M A F E_{i j t}=a_{0}+a_{1} D A G E_{i j t}+a_{2} L P M A F E_{i j t}+\mu_{i j t}
\end{aligned}
$$

\footnotetext{
${ }^{10}$ Brown (2001) shows that a model that incorporates the analyst-specific explanatory variables and a lagged accuracy variable offers the greatest explanatory power when compared to (i) a model with just lagged accuracy and forecast age variables and (ii) the full model above less the lagged accuracy variable. I obtain similar results and therefore employ the model in equation (3) throughout the rest of the calculations. Results, however, are not significantly different to those obtained when using either of the other two models (discussed in Brown, 2001).
} 


$$
\begin{gathered}
P M A F E_{i j t}=a_{0}+a_{1} D A G E_{i j t}+a_{2} D G E X P_{i j t}+a_{3} D C E X P_{i j t}+a_{4} D N C O S_{i j t} \\
+a_{5} D_{N S I G}+a_{i j t} D N O A N Y_{i j t}+a_{7} D F R E Q_{i j t}+a_{8} L P M A F E_{i j t}+\mu_{i j t}
\end{gathered}
$$

where $P M A F E_{i j t}$ is the measure of analyst $i$ 's forecast accuracy for firm $j$ for fiscal period ending at time $t$ and is calculated as presented in equation (4).

$$
P M A F E_{i j t}=\frac{A F E_{i j t}-\overline{A F E_{j t}}}{\overline{A F E_{j t}}}
$$

where $\mathrm{A} F E_{i j t}$ (absolute forecast error) is the absolute value of the difference between analyst $i$ 's earnings forecast for firm $j$ for fiscal period ending at time $t$ and the actual earnings for firm $j$ for fiscal period ending at time $t$ and $\overline{A F E_{j t}}$ is the mean absolute forecast error for firm $j$ for period $t$.

Since I am looking at a relative measure of forecast accuracy as the dependent variable, the analyst-specific explanatory variables are all defined in relative terms as well. Each variable is calculated as the difference between the value for that variable for analyst $i$ for firm $j$ for fiscal period ending at time $t$ and the average variable value for all analysts following firm $j$ at time $t$. An example of the calculation of this relative value will be given for each of the variables.

$\boldsymbol{D A} \boldsymbol{G} \boldsymbol{E}_{i j t}$ (Brown, Richardson and Schwager, 1987) is the forecast age defined as the number of days between the analyst's last earnings estimate and the company's year or quarter end less the average earnings forecast age. I would hypothesize that this variable will have a positive sign associated with it. The larger the age variable (and hence the older the forecast) the less accurate I would expect it to be and hence the positive sign associated with the age variable. 


$$
D A G E_{i j t}=\left(A G E_{i j t}-\overline{A G E_{j t}}\right)
$$

Where:

$A G E_{i j t}=$ Forecast age for analyst $i$ for security $j$ at time $t$.

$\overline{A G E_{j t}}=$ Average forecast age for all analysts following security $j$ at time $t$.

$\boldsymbol{D G E X P}_{i j t}$ (Clement, 1999) is a measure of the general experience of analyst $i$ and is calculated as the number of years that an analyst appears in the database less the average experience of all analysts following the firm for that year (or quarter). I would hypothesize this variable to have a negative sign associated with it. The more general experience an analyst has the larger this variable will be and the more accurate I would expect the analyst to be and hence the negative sign I hypothesize for this variable.

$$
D G E X P_{i j t}=\left(G E X P_{i t}-\overline{G E X P_{j t}}\right)
$$

Where:

$G E X P_{i t}=$ Years of general experience for analyst $i$ at time $t$.

$\overline{G E X P_{j t}}=$ Average years of general experience for all analysts following security $\mathrm{j}$ at time $\mathrm{t}$.

$\boldsymbol{D C E X P}_{i j t}$ (Mikhail, Walther and Willis, 1997) is analyst $i$ 's company-specific experience defined as the number of years that the analyst has been following a specific firm less the average company-specific experience of all analysts following the firm. I would hypothesize this variable to have a negative sign associated with it. The more company specific experience an analyst has the larger this variable will be and the more accurate I would expect the analyst to be and hence the negative sign I hypothesize for this variable. 


$$
D C E X P_{i j t}=\left(C E X P_{i j t}-\overline{C E X P_{j t}}\right)
$$

Where:

$C E X P_{i j t}=$ Years of company-specific experience for analyst $i$ for security $j$ at time $t$.

$\overline{C E X P_{j t}}=$ Average years of company-specific experience for all analysts following security $j$ at time $t$.

$\boldsymbol{D N C O S}_{i j t}$ (company complexity; Clement, 1999) and $\boldsymbol{D N S I G}_{i j t}$ (industry complexity; Clement, 1999) are proxies for the complexity of analyst $i$ 's job. The former (latter) variable is defined as the number of firms (two-digit SIGs) that analyst $i$ follows in period $t$ less the average number of firms (two-digit SIGs) followed by all analysts who follow firm $j$ for time period $t$. I would hypothesize these variables to have a positive sign associated with them. The more companies (industries) an analyst has to follow the less time the analyst has to study each company (industry). The less time an analyst has for each company (industry) the less accurate I would expect him to be and hence the positive sign I hypothesize for these variables.

$$
\begin{aligned}
& D_{N \operatorname{COS}_{i j t}}=\left(N \operatorname{NOS}_{i t}-\overline{N C O S_{j t}}\right) \\
& D N S I G_{i j t}=\left(N S I G_{i t}-\overline{N S I G_{j t}}\right)
\end{aligned}
$$

Where:

$N C O S_{i t}=$ Number of companies followed by analyst $i$ at time $t$.

$\overline{\operatorname{NCOS}_{j t}}=$ Average number of companies followed by all analysts following security $j$ at time $t$.

$N S I G_{i t}=$ Number of industries (SIG's) followed by analyst $i$ at time $t$. 
$\overline{N S I G_{j t}}=$ Average number of industries (SIG's) followed by all analysts following security $j$ at time $t$.

DNOANY $_{i j t}{ }^{11}$ (Clement, 1999) is a proxy for brokerage house size, and thus resources, for which analyst $i$ works. This variable is defined as the number of analysts that work for the same brokerage house that employs analyst $i$ less the average number of analysts employed at brokerage houses of other analysts that cover firm $j$ for period $t$. I would hypothesize this variable to have a negative sign associated with it. The more analysts that work for the brokerage house the more research help an analyst has available to him. The more research help and analyst has the more accurate I would expect him to be and hence the negative sign I hypothesize for this variable.

$$
D N O A N Y_{i j t}=\left(N O A N Y_{i t}-\overline{N O A N Y_{j t}}\right)
$$

Where:

$N O A N Y_{j t}=$ Number of analysts who work at the same brokerage house as analyst $i$ at time $t$.

$\overline{N O A N Y_{j t}}=$ Average number of analysts at each brokerage house for all analysts following security $j$ at time $t$.

DFRE $Q_{i j t}$ (Jacob, Lys and Neale, 1999) represents analyst $i$ 's forecast frequency and is defined as the number of forecasts made by the analyst for firm $j$ for period $t$ less the average number of forecasts made by all analysts who follow the firm during the same time period. I would hypothesize this variable to have a negative sign associated with it.

${ }^{11}$ Clement (1999) incorporates a dummy variable to indicate whether the brokerage house that a particular analyst works for is a top decile brokerage house in terms of size. I use a linear measure of brokerage house size instead because of the belief that brokerage house size effect would be better represented by a linear model than an integral model. 
The more frequent an analyst makes revisions to his forecasted earnings estimate the more closely we would expect him to be following the company. The more closely the analyst follows the company the more accurate I would expect him to be and hence the negative sign I hypothesize for this variable

$$
D_{F R E Q_{i j t}}=\left(F R E Q_{i j t}-\overline{F R E Q_{j t}}\right)
$$

Where:

$F R E Q_{i j t}=$ Number of forecasts made by analyst $i$ for security $j$ during time $t$.

$\overline{F R E Q_{j t}}=$ Average number of forecasts for all analysts following security $j$ during time $t$.

$\boldsymbol{L P M A F E}_{i j t}$ (Brown, 2001) is defined as the analyst's accuracy from the previous period and is equal to $P M A F E_{i j(t-1)}$. If there is no entry for the past time period then the observation is removed. I would hypothesize this variable to have a positive sign associated with it. I would expect an analyst who was more accurate last period to continue to be more accurate and an analyst who was less accurate to remain less accurate and hence the positive sign I hypothesize for this variable.

There is a limitation on $D G E X P_{i j t}$ and $D C E X P_{i j t}$ as calculated, in that the data only allows me to calculate experience relative to the start of the database. All analysts in the first full year of I/B/E/S data availability, 1983, will show up as having the same number of years of experience regardless of their actual general or company-specific experience. To have more meaningful results when incorporating these variables in the regression model, I eliminate analysts that were in the database in 1983. By eliminating these analysts I will ensure that the analysts who remain in the sample data set will have 
differences in their experience levels listed which actually represents real differences in their true experience levels.

In the initial analysis on predicted forecast accuracy, I essentially replicate the studies of Clement (1999) and Brown (2001) to determine whether the explanatory variables found in their studies continue to be significant with the extended sample, after the introduction of Regulation FD, and with the addition of the extra independent variables (number of analysts in the brokerage house and forecast frequency). For completeness, I present annual and pooled results for the entire sample period.

I next examine the predictive power of the model. Essentially, I want to examine whether the model can be used to identify the analysts that are most (and least) accurate in the next year using coefficients estimated from the current year. I use the regression coefficients from one year to predict the accuracy of the analysts for the next year. This results in 17 yearly averages and an overall pooled estimate. For example, I use the coefficient values generated from the 1994 regression and the actual explanatory variable values for a particular analyst following a particular firm for 1995 to get a predicted PMAFE for the analyst for 1995 for that firm. Each analyst is then classified as either a superior, inferior, or average analyst based on their predicted accuracy as compared to the other analysts following that firm during that same year. The top $10 \%$ of the analysts (based on their predicted PMAFE values) are classified as superior, the bottom $10 \%$ as inferior and the middle $80 \%$ as average ${ }^{12}$. I then compare the actual

\footnotetext{
${ }^{12}$ Because of the decision to include all estimates where there are at least 5 analysts following a company these percentages may not end up being truly reflected in the distribution of analysts classified as superior/average/inferior. The limitation is partially imposed by the fact that at least one analyst must be classified as both superior and inferior in each case (in order to facilitate comparisons amongst the groups). For
} 
mean PMAFEs for each classified group of analysts to see if they are significantly different from each other. If the analysts forecasting ability is predictable using this model I expect to find that the mean PMAFEs will be significantly different between the groups. This method is similar to that used by Brown (2001). If there is an increase in the predictive power of the model subsequent to Regulation FD, this would mean that the explanatory variables used in the model are more accurately able to predict analysts' forecast accuracy than they were able to do prior to regulation FD. If this is the case, I would also expect to find that differences in forecast accuracy between each analyst group would be greater, especially between superior and inferior analysts. I posit that such a change would imply that a variable that provided some explanatory power prior to the regulation (and which was not included in the models) is no longer important or relevant.

I also measure the impact of Regulation FD on each predicted analyst group by comparing, within each group, the average PMAFEs and the average AFEs before and after the implementation of the regulation. I repeat this test for quarterly forecasts using data from 1993 to 2001 . In this and the previous analyses, I employ a difference in means test to determine whether there are significant changes in relative and absolute forecast accuracy of the different analyst classifications.

I employ an additional method of evaluating the impact of Regulation FD on the predictive power of my model. I add a PostFD dummy variable that takes on a value of

example, if a security only had 5 analysts following it, the rules would classify one as superior, 1 as inferior, and 3 as average. In this case I would look at the actual distribution being the top $20 \%$ being classified as superior, the middle $60 \%$ as average, and the bottom $20 \%$ as inferior. Only when I have a minimum of 10 analysts following the security will I in fact get the distribution working out to $10 \% / 80 \% / 10 \%$. 
1 for fiscal ends after October of 2000 and a value of 0 otherwise. This extended model is presented in equation (12).

$$
\begin{aligned}
& \operatorname{PMAFE}_{i j t}=a_{0}+a_{1} D A G E_{i j t}+a_{2} D G E X P_{i j t}+a_{3} D C E X P_{i j t}+a_{4} D N C O S_{i j t} \\
& +a_{5} D_{N S I G}+a_{6 j t} D_{N O A N Y_{i j t}}+a_{7} D_{F R E Q_{i j t}}+a_{8} L_{P M A F E} E_{i j t}+a_{9} \text { PostFD }_{t}+\mu_{i j t}(12)
\end{aligned}
$$

The purpose of the test of this model (by adding the PostFD dummy variable) is to see if different predicted groups of analysts (superior/average/inferior) are affected to different degrees by the implementation of Regulation FD. Since I am using a relative measure of accuracy as my dependant variable (PMAFE) it, by definition, allows us to compare across time. However, since I am trying to test the impact of a change in regulation, the use of this relative measure hampers us since, if I look at all analysts as a group, I will find that the PostFD variable would be insignificant. However, if I test within each defined predicted group to see if the PostFD variable is significant I will be able to see if the regulation implementation does in fact affect different predicted groups differently. If I find that the PostFD variable is insignificant for all analyst classifications I could conclude that it is due to the fact that the implementation of Regulation FD does not affect the accuracy of analysts or that it affects all analysts equally. If, however, I find that the PostFD dummy variable is significant for different predicted groups of analysts it will suggest that the implementation of Regulation FD has, in fact, affected my ability to predict which analysts will be most accurate. 


\section{Chapter 5}

\section{Empirical findings and discussion}

This chapter presents the findings of this thesis. Section 1 analyzes the effects of Regulation FD on both the actual and relative forecast accuracy of analysts' earning estimates. Section 2 analyzes the effect on analysts on a per industry basis. Section 3 lists the results when looking at analysts who are consistently classified as superior, inferior, or average. Section 4 analyzes the analyst specific determinants of analysts' forecast accuracy and how/if they have changed since the implementation of Regulation FD. Section 5 looks at the difference in analysts' accuracy between different groups of analysts. These analysts are split into groups based on their predicted accuracy. Section 6 analyzes the effect of Regulation FD on the relative forecast accuracy of analysts who have been classified using a model based on analyst specific determinants. Section 7 then analyzes the effect of Regulation FD on the absolute forecast accuracy of analysts who have been classified into a group based on this model. 


\subsection{Effect of Regulation FD on actual relative and absolute forecast}

\section{accuracy}

In this section, I present the results of changes in actual analyst earnings estimate performance after the implementation of Regulation FD. I classify analysts as superior, average and inferior based on their performance one year immediately prior to October 2000 by comparing PMAFEs of analysts following the same firm during this period. I then see how these analysts perform, both on a relative basis and on an absolute basis, in the year immediately following Regulation FD implementation. Results for this analysis are presented in Panels A (relative) and B (absolute) of Table 2. I find that analysts that were superior prior to Regulation FD perform significantly worse on a relative basis after October 2000. Average analysts also perform relatively worse in the post-FD period. Inferior analysts, however, improve their performance relative to other analysts.

Panel A of Table 2 indicates that the analysts that were classified as superior prior to Regulation FD decline in relative forecast accuracy by 0.719 , while analysts who were classified as inferior prior to Regulation FD increased in relative accuracy by 0.877. If you look at their post-FD PMAFE values you see that the three groups now have a very small difference in relative accuracy between them, when compared to the differences which were apparent in the pre-FD period. So, for example, if the actual average earnings forecast error for a firm (taking the average of all the analysts errors for that firm) was $\$ 1.00$, prior to Regulation FD the average superior analyst would have an earnings forecast error of $\$ 0.282$ (since their pre-FD PMAFE was -0.718). Post-FD, however, this superior group, on average, would have an earnings forecast 
error of $\$ 1.001$ (since their PMAFE has now increased to 0.001). This difference in relative forecast error is significant both for the superior, inferior, and to a lesser extent, for the average analysts. The inferior analysts' performance has improved and their improvement is the largest magnitude change of all.

Panel B of Table 2 indicates that the analysts that were classified as superior prior to Regulation FD decline in absolute forecast accuracy by 0.164 . So, for example, if the actual earnings for a firm were $\$ 10.00$, prior to Regulation FD the average superior analyst would have forecasted earnings of $\$ 9.60$ or $\$ 10.40$ (since their pre-FD $A F E$ was 0.040 ). Post-FD, however, this superior group, on average, would have forecasted earnings of $\$ 7.96$ or $\$ 12.04$ (since their $A F E$ has now increased to 0.204 ). This increase in absolute forecast error is significant both for the superior, and, to a lesser extent, for the average analyst. The inferior analyst's performance has declined, but this result is not statistically significant.

One of the potential problems with the method with which I select the sample is that it leads to survivorship bias ${ }^{13}$. I find that the sample loses $36 \%^{14}$ of the superior analyst sample in the post-FD period. In other words, $36 \%$ of the analysts that were classified as superior do not make a forecast for that same firm immediately subsequent to regulation implementation. More importantly, I lose $59 \%$ of the inferior analyst sample. This makes intuitive sense. I would expect that badly performing analysts would more likely stop following a particular company, thus the disparity in percentage of sample lost. This, however, could lead to an artificially conservative bias for the

\footnotetext{
${ }^{13}$ This survivorship bias is due to the fact that only analysts who make estimates in both the pre- and post-FD period are kept in the sample group

${ }^{14}$ Results not tabulated.
} 
relative and absolute performance of, especially, the inferior analysts as the worst performing analysts could be excluded from the analyses.

To circumvent this issue, I compare relative and absolute performance using a sample of analysts that make forecasts in both the pre- and post-FD periods. After constructing this sample, I then classify analysts as superior, average or inferior, knowing that these analysts will remain in the post-FD period.

Results of this analysis are presented in Panels C and D of Table 2. As is expected, the greatest difference that I find using this method is that, as shown in Panel $\mathrm{D}$, there is also a significant deterioration in the performance of inferior analysts (the decrease in their absolute accuracy is now significant whereas it was not before). Other results are essentially the same.

The findings, using the analyses showed so far, suggest that the implementation of Regulation FD has had a differential impact on the ability and accuracy of analysts. Analysts who were doing well immediately before the implementation of Regulation FD seem to have lost most of their advantage over the rest of the analysts while analysts who were doing poorly immediately before the implementation seem to have benefited relative to other analysts. Inferior analysts have seen their absolute performance deteriorate somewhat; however, the size of the deterioration is nowhere near the magnitude of the deterioration by the other classifications of analysts.

The exact reasons for these changes are not shown here; however, it could well be that two factors are influencing the results. The first factor that could be influencing results is the access to inside information that some analysts would have had. If the implementation of Regulation FD has stopped companies from giving out inside 
information to analysts, may negatively impact the accuracy of the analysts in the postFD period. It would be easy to explain why this would affect different groups of analysts in different magnitudes. If I posit that the analysts who were superior in the pre-FD period had access to more inside information than average or inferior analysts did, it would be easy to see why they would sustain a larger negative impact on their earnings estimates accuracy after Regulation FD came into effect. The second factor that could be influencing the results is the possible increase in information that has been released to the markets by companies since the implementation of Regulation FD. If companies have in fact increased their information flows to the market, this would increase the information available at any time to the analysts and should therefore increase their accuracy. This second influence though should have a positive influence on the accuracy of analysts post-FD, and should be more equal across analyst classifications (since all analysts would have access to the same information which has been made public). This increased information flow post-FD (if present) could, in fact, be hiding some of the negative influence of a reduction in inside information. 


\subsection{Effect of Regulation FD on superior, average and inferior analysts by industry}

Inherent in every industry is a different set of competitive rules, different business practices, and different management styles, which could make company information flows significantly different between industries. In this section, I present the results of the differential impact of Regulation FD across industries

In Table 3, I compare the average PMAFE and AFE, for all analysts who have been classified as superior in the pre-FD period, for the pre and post-FD period. The findings are very consistent with what was found for the overall analysis. All of the superior analysts have shown a decrease in both their relative and absolute accuracy since the implementation of Regulation FD. It can be seen though that the changes in accuracy between the pre- and post-FD periods can vary largely depending on which particular industry is being considered. This is especially true when looking at the measures of change in the absolute accuracy of analysts. The change in AFE between the pre- and post-FD periods ranges from a low of -0.0047 (for healthcare) to -0.317 (for energy).

Table 4 shows the same comparison for the inferior analysts from the pre-FD period. Here again I find that in relative terms all of the analysts increase their accuracy greatly; however, when looking in absolute terms I find little evidence that there is a significant change from the pre- to the post-FD period. Again the magnitude of the changes in accuracy between industries can vary a fair amount. However, with the sample sizes starting to get fairly small (as I break the original sample up into industry 
specific subsamples), it is hard to compare these magnitudes with any level of confidence.

Table 5 repeats the comparison of relative and absolute earning estimate accuracy for analysts who were defined as average before the introduction of Regulation FD. These findings are consistent with what I have found with the other analysts' classifications. The average analysts have consistently (across all industry classifications) shown a decrease in both relative and absolute accuracy with the implementation of Regulation FD. Again, when evaluating the change in absolute forecast accuracy, I notice that the smallest change was in the healthcare industry ($0.059)$ while the energy industry $(-0.318)$ had the largest change. 


\subsection{Effect of Regulation FD on consistently superior, average and inferior analysts}

In the previous sections, I categorize analysts as superior, average or inferior based on their annual earnings forecast in the fiscal year immediately prior to the implementation of Regulation FD. However, if there is no persistent performance among analysts across time, these findings may be spurious in that an analyst that performs well (poorly) in one period may not necessarily perform well (poorly) in the next period. Sinha, Brown and Das (1997) suggest that there is persistence in analyst performance across time especially for superior analysts. In their study, persistence in the performance of inferior analysts is found to be only marginally significant although one confounding factor in their analyses is that there was no accounting for analysts that discontinue making forecasts for a particular company. This would apply more to inferior analysts as they would more likely be required to stop coverage of a particular company if their forecast accuracy was poor.

I analyze the pre-FD and post-FD performance of analysts that are consistently superior, average or inferior in the pre-FD period on both a relative and absolute basis. Panel A (relative) and Panel B (absolute) of Table 6 presents results of analysts that are classified as superior/average/inferior if their relative forecast accuracy in the four quarters immediately prior to Regulation FD is in the top quartile / middle 50 percent / bottom quartile in each of the four quarters ${ }^{15}$. Only analysts that make quarterly forecasts in the two quarters subsequent to Regulation FD are included in this sample.

\footnotetext{
${ }^{15}$ The choice of defining an analyst as consistently superior on the basis of four consecutive quarters was done for two reasons. First, this is the same definition of consistent superiority as Sinha et al. (1997) use and so makes comparison easier.
} 
I find that the relative performance of consistently superior analysts has significantly (at the $5 \%$ level) declined post-FD whereas the performance of consistently inferior analysts has improved relative to other analysts albeit only marginally (only significant at the $10 \%$ level). Absolute forecast error is significantly greater in the post-FD period for both superior and average analysts (at the 5\% and $1 \%$ levels respectively) whereas there is an insignificant change in the absolute forecast error of inferior analysts.

As is evident by the number of observations in this analysis, my sample restrictions considerably reduce the analysts that are appropriate for my sample. Relaxing my restrictions, in Panel C (relative) and Panel D (absolute) of Table 6, I present the results of analysts that are classified as superior/average/inferior if their relative forecast accuracy in the two quarters immediately prior to Regulation FD is in the top quartile / middle 50 percent / bottom quartile in each of the two quarters. Results for relative performance are more significant with these classifications. I find that superior and average analysts perform significantly worse and inferior analysts perform significantly better post-FD, all significant at the $1 \%$ level. Absolute forecast accuracy declines for superior and average analysts and improves for inferior analysts.

Brown (2001) has suggested that analysis of annual earnings forecasts provides more explanatory power than analysis of quarterly earnings forecasts do. In Table 7, I present the results of analysts that have been consistently superior, average or inferior in their annual earnings forecast where an analyst is classified as superior/average/inferior if their relative forecast accuracy in the two years prior to

Second, choosing a longer period than four quarters would reduce the sample size to such a degree that no real valid conclusions could be made. 
Regulation FD is in the top quartile/ middle 50 percent / bottom quartile in each of the two years. Only analysts that make a forecast in the year after the implementation of the regulation are included in the sample set. As the results show, the sample sizes are much larger using annual forecasts and therefore inferences made based on these results are more powerful.

I find that the relative performances of superior and average analysts have significantly declined post-FD and that inferior analysts have significantly improved their performance on a relative basis. All findings are significant at the $1 \%$ level and are consistent with my findings in Panel $\mathrm{C}$ of Table 3. I also find that the absolute forecast accuracy of all three analyst groups decline significantly post-FD although the decline is only marginally significant for the inferior analysts (only significant at the $10 \%$ level). The former result is inconsistent with the findings of Mohanram and Sunder (2002); however, the latter is consistent.

In Table 8, I present the results of the differences in absolute forecast errors between each of the three analyst groups. Panel A shows the differences in the pre-FD period and Panel B shows the differences in the post-FD period. Since the classification of analysts into the three groups is done in the pre-FD period, I would naturally expect to find superior analysts outperforming both average and inferior analysts and average analysts outperforming inferior analysts.

More interestingly, in the comparison of absolute forecast errors between the three groups in the post-FD period, the only difference that is marginally significant is the difference in forecast errors between the superior and average analysts and my finding here is that average analysts actually outperform superior analysts in the post- 
FD period (significant at the $10 \%$ level) when looking at the annual forecasts. I also find that in the post-FD period even the inferior analysts outperform the superior analysts (although the difference is not found to be significant at any level). All other differences are insignificantly different using both quarterly and annual forecasts. These results provide strong evidence that the implementation of Regulation FD has created a level playing field.

The findings with respect to the effects on analysts who are consistently superior, average, or inferior are fairly consistent across all of the analyses. All of the tests suggest that the differences in earnings estimate accuracy has disappeared since the implementation of Regulation FD. These results support the theory that one of the characteristic differences between analysts that allowed certain analysts to be either consistently superior (inferior) was the particular analyst's access (lack of access) to inside information on the firms which they were covering. Since one of the primary goals of the SEC, when it implemented Regulation FD, was to make a more level playing field on which analysts compete, I would say that they seem to have succeeded in that regard. 


\subsection{Determinants of Forecast Accuracy}

The next issue that I examine in this thesis is if the determinants of analysts forecasting accuracy have changed since the implementation of Regulation FD. In order to do this, I run regressions on analysts attributes against their relative forecast accuracy to see if any of these attributes are statistically significant determinants. The results of my initial regression analysis on this area of research are presented in Tables 9, 10, and 11. Table 9 shows the regression analysis for the regression model in equation (1), Table 10 shows the regression analysis for the regression model in equation (2), while Table 11 shows the analysis for the regression model in equation (3). It is clear from the results in these tables that all 3 models are useful in explaining the relative accuracy of analysts' earnings estimates. However, the model represented by equation (3), by combining the two previous models, and adding the number of analysts and frequency of earnings estimates, explains the most overall variation of the dependant variable of all of the models. The Adjusted $\mathrm{R}^{2}$ of the models is 0.1312 , 0.1413 , and 0.1635 respectively. Since equation (3) seems to best model the relationship between analysts' characteristics and their earnings estimate accuracy this is the one that I choose to use exclusively going forward with my examination of determining analysts' accuracy.

Table 11 provides the regression results, annually and for the entire 1984-2001 sample, using the regression model in equation (3). Consistent with Clement (1999) and Brown (2001), I find that there is a significant, negative relationship between 
forecast age and forecast accuracy ${ }^{16}$. Also, as was found by Clement (1999), I find that the proxy for brokerage house size (the number of analysts employed by the firm) and the analyst's firm-specific experience are positively related to forecast accuracy. I also find a significant negative relationship between the number of industries an analyst covers and his forecast accuracy as does Clement (1999). However, I do not find a significant relationship between the number of companies followed by an analyst and his forecast accuracy as does Clement (1999). Consistent with the findings of Jacob, Lys and Neale (2000), I find that when firm-specific experience is included in the model, there is no significant relationship between an analyst's general experience and forecast accuracy [this finding is consistent in both regressions on equation (1) and (3) where both firm and general experience are included in the regression]. Mikhail, Walther and Willis (1997) document a positive relationship between forecast frequency and forecast accuracy; the results found here are consistent with this finding. Finally, I find a positive relationship between past forecast accuracy and current forecast accuracy as was found by Brown (2001).

One of the issues which must be looked at is the potential for there to be autocorrelation between the residuals of the regression. If there is autocorrelation between the residuals then the variance for each of the variables may be underestimated (and hence the t-statistic may be overestimated) and we will not have the best estimates for the values of the independent variables. In order to test for autocorrelation I run a Durbin-Watson test (as described in Appendix 1) to see if this is an issue. The calculated Durbin-Watson value of 1.866 leads me to reject the belief that there is

\footnotetext{
${ }^{16} \mathrm{Keep}$ in mind that a lower value for PMAFE means that the analyst's forecast is relatively more accurate.
} 
autocorrelation between the residuals and hence this is no something that is an issue with this regression.

In the analysis of the effect of Regulation FD on this model, one interesting finding in Table 11 is that the adjusted $\mathrm{R}^{2}$ is substantially higher in 2001 than in any year prior to 2000 . In 2001, this value is 0.42 compared to 0.20 in 1999 . This result suggests that the model has become more powerful in determining the forecast accuracy of analysts in $2001^{17}$. One possible explanation for this is that prior to the implementation of Regulation FD (in October 2000), one factor that is not accounted for in the model but could have contributed to the accuracy of the analysts is the access to and use of selective pre-announcement guidance. Subsequent to Regulation FD, since analysts do not have privileged access to company information (if Regulation FD has succeeded in changing companies actions), the accuracy of the analysts' earnings forecast is explained to a greater degree by the other independent variables included in the model, thus the higher $\mathrm{R}^{2}$.

Table 11 also shows us that the independent variable for number of analysts (DNOANY) has become insignificant in the 2001 time period (post Regulation FD). This is as an interesting finding in that this independent variable was found to be significant in every year up to 2001. If the implementation of Regulation FD has led to this change in the number of analysts being significant (which is being used as a proxy for brokerage size) then it could be that access to inside information and brokerage size

\footnotetext{
${ }^{17}$ I run a Chow Test to test and see if there has been a structural change in the model using the implementation of regulation FD as the break point. This test will indicate if there has been a structural change in the model which would explain the higher R2 value found in the post Regulation FD period. The calculated F value (168.00) makes me reject the null hypothesis and believe that there was a structural change. The Chow Test model used for this test is described in Appendix 2.
} 
are correlated (since Regulation FD is designed to stop access to inside information by the analysts). This would as well make logical sense given the state of the capital markets, due to the fact that the larger brokerages would likely have closer ties to companies (through the brokerage houses banking arm) and therefore may likely have access to more inside information. This may be another indication that the implementation of Regulation FD has affected the distribution of inside information and seems to have leveled the playing field for different sized brokerage houses. With only one time period in the post Regulation FD time period it is hard to conclude if this is in fact a lasting effect of the implementation of Regulation FD or is in fact just a temporary anomaly. If through further testing as time goes on this change in the significance of brokerage size remains then these conclusions would be validated.

Table 12 shows the correlation matrix for the independent variables in model 3. This allows us to see which of the independent variables are related to each other. From this table it can be seen that the variables that would be expected to have some correlation to each other are in fact the variables that are related. The variable for relative age of forecast estimate (DAGE) and the relative frequency of analysts estimates (DFREQ) are positively related. As well analysts relative general experience (DGEXP) and relative company specific experience (DCEXP) are related to each other. There are no unexpected correlations here which would lead to reconsidering the design of the model or the independent variables chosen to be included in the model. 


\subsection{Differential Predicted Forecast Accuracy}

Tables 13 through 15 present the results of tests of differences in mean PMAFE between predicted superior, average and inferior analyst groups. Table 13 presents the results of the comparison of the PMAFEs of the predicted superior group to the predicted inferior group. In every one of the 17 years the difference is negative and significant at the $1 \%$ level, and, as would be expected, the predicted superior group has a lower level of relative forecast error than the predicted inferior group. Overall, I see that the difference is -1.041 between the two groups with the predicted superior analysts having a mean PMAFE of -0.258 while the predicted inferior analysts have a mean $P M A F E$ of 0.783 . This means that if the average earnings estimate error of all analysts following a firm was $\$ 1.00$ then the predicted superior analysts would have an average earnings estimate error of $\$ 0.742$ while the inferior analysts would have an average earnings forecast error of $\$ 1.783$.

Table 14 presents the results of the comparison of the PMAFEs of the superior predicted analysts to those of the analysts who were predicted as average. Again, in all 17 years and overall, the superior analysts' mean PMAFE is significantly less than the average analysts' mean $P M A F E$ at the $1 \%$ level. The difference between the two in this case is -0.1601 when looking at the pooled results.

Table 15 presents the results of the comparison of the predicted inferior analysts to the predicted average analysts. Following the previous pattern, in all 17 years the mean $P M A F E$ for the inferior analysts is larger than that for average analysts. The size difference, -0.8810 , is significant at the $1 \%$ level and is noticeably larger than that between the predicted average and superior analysts. 
When comparing the difference in mean PMAFE during the post-FD period to any of the prior periods, I see that the difference is significantly larger than it is in any of the pre-FD years between each of the three analyst groups ${ }^{18}$. This result is consistent with my finding of higher adjusted $\mathrm{R}^{2}$ associated with the model since the implementation of regulation FD, in the previous section, in that it appears that the predictive ability of my model has improved post-FD. The model is better able to identify analysts that would be expected to perform relatively better (and worse) than the average analyst. Therefore, the difference in relative forecast accuracy increases post-FD, as the analysts predicted to be superior in 2001 are relatively more accurate than their inferior counterparts would have been in years prior to the implementation of the regulation. Once again, this suggests that the explanatory variables in the model now explain more of the variation in forecast accuracy across analysts than previously.

\footnotetext{
${ }^{18}$ To determine whether this and subsequent results are driven by outliers, I perform this and all subsequent analyses after removing analyst-firm-years whose PMAFE values fall below the 1st and above the 99th percentile. The results and conclusions are not materially affected by this restriction.
} 


\subsection{Effect of Regulation FD on Relative Forecast Accuracy for Model \\ Classified Analysts}

Table 16 presents the results of the regression for the superior, inferior, and average analyst groups for annual earnings forecast accuracy using equation (12), which incorporates the additional PostFD dummy variable. In this analysis, I find that the PostFD variable is found to be significant across each of the analyst groups. The negative sign associated with the PostFD dummy variable, for the superior analysts, once again suggests that the implementation of Regulation FD has made the model more accurate at predicting which analysts will give superior earnings estimates. The positive sign associated with the PostFD dummy variable for the inferior analysts tell us that the model is now better able to predict inferior analysts subsequent to Regulation FD as well.

I also examine the differential effect of Regulation FD on the three analyst groups by comparing mean $P M A F E$ values before and after regulation implementation for each of the three groups. Table 17 presents the results of this analysis. For reasons explained immediately below, I run the analyses using three different pre-Regulation FD samples. First, I use the entire pre-FD sample. The second pre-FD sample uses data from 1993 to 1998. Although Regulation FD was implemented in October of 2000, there is anecdotal evidence that firms started complying with the regulation well before the actual implementation date. Therefore, to take this into account, I use a pre-FD definition of 1993 to 1998 . This 5-year period gives enough data to test efficiently and should be before any early implementation effects may have taken place (1993 is chosen as the initial year because $\mathrm{I} / \mathrm{B} / \mathrm{E} / \mathrm{S}$ concedes that data prior to this year are less 
reliable than data from after 1993). The third pre-FD sample is defined as 1999 to October of 2000. This is an approximately matched time period that represents the most recent pre-FD sample available.

Results for the predicted inferior analysts are consistent across all measures of the pre-FD period and for both annual and quarterly analyses. The difference between mean $P M A F E$ in the pre- and post-FD periods is negative and significant in all cases. Once again, this suggests that the predicted inferior analysts are performing relatively worse subsequent to the regulation (which again points to the model being a better predictor of which analysts will give poor earnings estimates). Results for the predicted average analysts are more ambiguous. With annual forecasts, only with the entire sample as the pre-FD period is the difference in mean $P M A F E$ between the two periods significant and positive. Quarterly results are more consistent. The predicted average analysts perform significantly better regardless of the pre-FD measure used. The results for superior analysts are only marginally significant using quarterly data. However, using annual data, the difference in mean $P M A F E$ is significant and positive at the $1 \%$ level in all cases. This suggests that the predicted superior analysts perform relatively better after the implementation of the regulation than prior to it compared to average and inferior predicted analysts.

Again all of the findings in this research suggest that the model is better able to predict which analysts will make the best and worst earnings estimates since the implementation of Regulation FD. The results also suggest that these predictions, as to which analysts will be the most accurate, are more reliable when looking at the analysts' annual earnings estimates as compared to their quarterly earnings estimates. 


\subsection{Effect of Regulation FD on Absolute Forecast Accuracy for Model Classified Analysts}

The previous sections have presented results on the impact of the change in regulation on the relative ability of different types of predicted analysts. In Table 18, I present the results of the effect of Regulation FD on absolute forecast accuracy of the predicted analyst groups. I examine the changes in the absolute forecast error $(A F E)$ for the different types of analyst between the pre-FD and post-FD time periods. Using the annual earnings forecast sample, I find that the predicted inferior analysts perform worse than they did prior to Regulation FD when using pre-FD definitions of 1993 1998 and 1999 to Oct. of 2000 . Interestingly, I get the opposite result when using the entire pre-FD sample. However, as Jacob, Lys and Neale (1999) have shown that the absolute forecast measure is difficult to compare across times and I/B/E/S has indicated that the earlier data may not be quite as reliable, I discount this result as not being representative of the effect of Regulation FD but due to other influences on analyst's accuracy which have taken place over the time period. ${ }^{19}$ The effect of Regulation FD on the predicted average analysts is only marginally significant and negative which suggests that these analysts perform slightly worse in the post Regulation FD period. Although the difference in the two periods is negative for the predicted superior

${ }^{19}$ In order to check this belief I plot the average absolute forecast error (AFE) for all analysts for each year in the data set. This plot can be seen in Figure 1. This plot shows that prior to 1990 the average $A F E$ was much higher than it was after the 1990 period. The 1990 to 1993 period seems to show a significant increase in the absolute accuracy of analysts. This would suggest that something took place during this period which increased the accuracy of analysts' estimates greatly. The higher values associated with AFE in the pre-1990 time period would influence the results I am getting and would be the likely cause of us finding an increase in analysts accuracy (as represented by $A F E$ ) when comparing the pre-FD period as the whole sample. I attribute these contrary findings to be due to the influence of the pre-1990 time period. 
analysts, the difference is statistically insignificant. Quarterly results are similar for superior and inferior analysts' groups, however, I find that the predicted average analysts perform significantly worse in the post-FD period. These findings suggest that the overall effect on predicted analysts has been to decrease their absolute earnings estimate accuracy $(A F E)$ since the implementation of Regulation FD. I do note that it seems to have affected the inferior analysts the most out of any of the groups. 


\section{Chapter 6}

\section{Conclusion}

The majority of security analysts contend that the deterioration in the quality and quantity of information revealed by companies after the implementation of Regulation FD adversely affects their ability to accurately forecast earnings. In this thesis, I empirically test the differential impact of the regulation on superior, average and inferior analysts classified as such based on their relative forecast accuracy. I find that all analysts are less accurate subsequent to the implementation of the regulation. However, I also find that superior analysts are relatively less accurate than they were prior to the regulation when compared to average and inferior analysts, and hence have borne the brunt of the negative impact of Regulation FD on analysts' earnings estimate accuracy.

To substantiate my findings, I examine the change in predictive power of an analystspecific model used to estimate relative forecast accuracy. I find that this model has greater power in predicting which analysts will be superior and inferior subsequent to regulation implementation. This suggests that a previously important explanatory variable, which is not accounted for in this model, is no longer relevant. I believe this variable would represent the selective guidance received by some analysts before the implementation of Regulation FD, which they now no longer receive.

These results suggest that one of the reasons for the superior performance of some analysts prior to Regulation FD was their access to selective guidance by firms. If the differential information interpretational skill was the sole factor in differentiating 
performance, I would expect to find especially relative, but also absolute, performance remain fairly constant across the two periods. I do not find this to be the case.

The model which was originally developed by Clement (1999), and has since been expanded by many other researchers, seems to be an even better predictor of analyst accuracy since the implementation of Regulation FD. I attribute this to the fact that the model now includes a larger portion of the total variables that affect analyst performance than it did before the implementation of Regulation FD. Since the selective guidance variable is likely to no longer influence the accuracy of analysts, the variables included in the model better predict the analysts' accuracy. One of the unexpected results of the implementation of Regulation FD, that I found, is that the model of the determinants of analysts' earnings estimates accuracy first put forward by Clement (1999) is now a better fitting model than it was previously. With the ongoing work of Brown and Mohammad (2001) showing that there is the potential for actual trading models which can earn abnormal returns, on the basis of using the model of analysts' accuracy, the fact that the model is now even a better predictor of analysts' forecast accuracy becomes increasingly important.

I also examine the absolute forecast accuracy differences between analysts that were classified as superior, average or inferior immediately prior to the implementation of Regulation FD. I find that differences in forecast accuracy between these groups are insignificant. Based on this result, I conclude that Regulation FD has created a more level playing field, at least within the analyst community. This would mean that the SEC has accomplished at least one of its goals with Regulation FD, which was to put analysts on a more equal footing with each other. What is less clear is the effects on the 
market that the decrease in the accuracy of analysts' earnings estimates will have over time. This potentially negative impact is something the SEC will have to weigh when deciding on how and if to rework Regulation FD. 


\section{References}

Brown, L., 2001. How important is past analyst accuracy?, Financial Analyst Journal $57,44-49$.

Brown, L. and E. Mohammad, 2001. Profiting from predicting individual analyst earnings forecast accuracy, Working paper, Georgia State University.

Brown, L., G. Richardson, and S. Schwager, 1987. An information interpretation of financial analysts superiority in forecasting earnings, Journal of Accounting Research 25, 49-67.

Brown, L. and M. Rozeff, 1979. Univariate time series models of quarterly accounting earnings per share. A proposed model., Journal of Accounting Research 17, 179 -189 .

Brown, L. and M. Rozeff, 1980. Analysts can forecast accurately, Journal of Portfolio Management 6, 31 - 34 .

Butler K., and L. Lang, 1991. The forecast accuracy of individual analysts: Evidence of systematic optimism and pessimism, Journal of Accounting Research 29, 150 $-156$.

Clement, M., 1999. Analyst forecast accuracy: Do ability, resources, and portfolio complexity matter?, Journal of Accounting and Economics 27, 285-303.

Heflin, F., K. Subramanyam, and Y. Zhang, 2001. Regulation FD and the financial information environment, Working paper, Purdue University.

Jacob, J., T. Lys, and M. Neale, 1999. Expertise in forecasting Performance of security analysts, Journal of Accounting and Economics 28, 51-82.

Kross, W., B. Ro, and D. Schroeder, 1990. Earnings expectations: The analysts' information advantage, Accounting Review 65, 461-476.

Mikhail, M. B. Walther and R. Willis, 1997. Do security analysts improve their performance with experience?, Journal of Accounting Research 35, 131-157.

Mohanram, P., and S. Sunder, 2002. Has Regulation Fair Disclosure affected financial analysts' ability to forecast earnings?, Working paper, New York University.

O'Brien, P., 1988. Analysts' forecasts as earnings expectations, Journal of Accounting and Economics 10, $53-83$. 
O'Brien, P., 1990. Forecast accuracy of individual analysts in nine industries, Journal of Accounting Research 28, 286 - 304.

Sinha, P., L. Brown, and S. Das, 1997. A re-examination of financial analysts' differential earnings forecast accuracy, Contemporary Accounting Research 14, $1-42$.

Stickel, S., 1992. Reputation and performance among security analysts, Journal of Finance 47, 1811-1837. 
Table 1

Summary Statistics

This table provides yearly summary statistics for the sample. Regulation FD went into effect on October 23, 2000, therefore the pre-FD period represents all fiscal year ends in 2000 prior to this date and the post-FD period represents all fiscal year ends in 2000 after this date.

\begin{tabular}{lcccc}
\hline Year & $\begin{array}{c}\text { Number of } \\
\text { Companies }\end{array}$ & $\begin{array}{c}\text { Number of } \\
\text { Analysts }\end{array}$ & $\begin{array}{c}\text { Number of } \\
\text { Brokers }\end{array}$ & $\begin{array}{c}\text { Number of } \\
\text { Observations }\end{array}$ \\
\hline 1984 & 753 & 987 & 55 & 11,673 \\
1985 & 760 & 1,118 & 70 & 13,666 \\
1986 & 1,004 & 1,212 & 80 & 16,708 \\
1987 & 1,078 & 1,249 & 72 & 17,023 \\
1988 & 1,273 & 1,300 & 113 & 17,270 \\
1989 & 1,406 & 1,390 & 122 & 17,211 \\
1990 & 1,364 & 1,393 & 139 & 15,603 \\
1991 & 1,459 & 1,547 & 130 & 18,214 \\
1992 & 1,476 & 1,551 & 141 & 19,014 \\
1993 & 1,507 & 1,452 & 147 & 19,445 \\
1994 & 1,654 & 1,499 & 135 & 19,430 \\
1995 & 1,751 & 1,559 & 140 & 19,747 \\
1996 & 1,832 & 1,694 & 156 & 20,915 \\
1997 & 1,975 & 1,861 & 159 & 21,364 \\
1998 & 2,125 & 2,087 & 189 & 22,366 \\
1999 & 2,123 & 2,320 & 191 & 22,825 \\
2000 -all & 1,939 & 2,334 & 190 & 21,594 \\
2000 -pre-FD & 551 & 803 & 63 & 5,795 \\
2000 -post-FD & 1,388 & 1,531 & 127 & 15,799 \\
2001 & 657 & 1,780 & 159 & 7,604 \\
\hline & & & & \\
& & & & 139 \\
\hline
\end{tabular}


Table 2

Differences in relative and absolute forecast accuracy for actual analyst groups in the pre- and post-FD periods

This table shows the mean relative and absolute forecast accuracy for analysts classified as superior, average or inferior prior to the implementation of Regulation FD and compares their forecast accuracy during the pre- and post-FD periods. An analyst is classified as superior/average/inferior if his relative forecast accuracy, measured by PMAFE, is in the top decile/middle 80 percentile/bottom decile of all analysts making forecasts for the same firm in the same year during the year immediately prior to regulation implementation (October 1999 to September 2000). In Panel A (B), results are presented for relative (absolute) forecast accuracy of analysts where analysts are classified regardless of whether they continue to cover the firm in the post-FD period. In Panel C (D), results are presented for relative (absolute) forecast accuracy where only analysts that make forecasts in the pre- and post-FD periods are included. These analysts are then classified as superior, average or inferior. Post-FD results are based on analysts' forecasts during the October 2000 to September 2001 time period. The significance and the associated t-Statistic of each difference are shown as well as the number of observations in each group.

Panel A. PMAFE values for analysts during the pre- and post-FD periods (analysts classified prior to matching)

\begin{tabular}{lrrrrr}
\hline $\begin{array}{l}\text { Analyst } \\
\text { Type }\end{array}$ & $\begin{array}{r}\text { Pre-FD } \\
\text { Mean PMAFE }\end{array}$ & $\begin{array}{r}\text { Post-FD } \\
\text { Mean PMAFE }\end{array}$ & $\begin{array}{r}\text { Difference in } \\
\text { Mean PMAFE }\end{array}$ & t-Stat. & N \\
\hline Superior & -0.718 & 0.001 & $-0.719 * * *$ & $(-47.35)$ & 5,253 \\
Average & -0.171 & 0.022 & $-0.193 * * *$ & $(-19.85)$ & 12,803 \\
Inferior & 1.057 & 0.179 & $0.877 * * *$ & $(26.44)$ & 2,499 \\
\hline
\end{tabular}

Panel B. AFE values for analysts during the pre- and post-FD periods (analysts classified prior to matching)

\begin{tabular}{lrrrrr}
\hline $\begin{array}{l}\text { Analyst } \\
\text { Type }\end{array}$ & $\begin{array}{r}\text { Pre-FD } \\
\text { Mean AFE }\end{array}$ & $\begin{array}{r}\text { Post-FD } \\
\text { Mean AFE }\end{array}$ & $\begin{array}{r}\text { Difference in } \\
\text { Mean AFE }\end{array}$ & t-Stat. & N \\
\hline Superior & 0.040 & 0.204 & $-0.164 * * *$ & $(-16.80)$ & 5,254 \\
Average & 0.128 & 0.261 & $-0.133^{* * *}$ & $(-19.35)$ & 12,809 \\
Inferior & 0.220 & 0.244 & -0.024 & $(-1.33)$ & 2,501 \\
\hline
\end{tabular}

Panel C. PMAFE values analysts during the pre- and post-FD periods (analysts classified after matching)

\begin{tabular}{lrrrrr}
\hline $\begin{array}{l}\text { Analyst } \\
\text { Type }\end{array}$ & $\begin{array}{r}\text { Pre-FD } \\
\text { Mean PMAFE }\end{array}$ & $\begin{array}{r}\text { Post-FD } \\
\text { Mean PMAFE }\end{array}$ & $\begin{array}{r}\text { Difference in } \\
\text { Mean PMAFE }\end{array}$ & t-Stat. & N \\
\hline Superior & -0.657 & -0.029 & $-0.628 * * *$ & $(-43.25)$ & 4,831 \\
Average & -0.083 & -0.027 & $-0.056^{* * *}$ & $(-5.50)$ & 10,325 \\
Inferior & 1.073 & 0.112 & $0.961 * * *$ & $(36.59)$ & 3,758 \\
\hline
\end{tabular}

Panel D. AFE values analysts during the pre- and post-FD periods (analysts classified after matching)

\begin{tabular}{lrrrrr}
\hline $\begin{array}{l}\text { Analyst } \\
\text { Type }\end{array}$ & $\begin{array}{r}\text { Pre-FD } \\
\text { Mean AFE }\end{array}$ & $\begin{array}{r}\text { Post-FD } \\
\text { Mean AFE }\end{array}$ & $\begin{array}{r}\text { Difference in } \\
\text { Mean AFE }\end{array}$ & t-Stat. & N \\
\hline Superior & 0.042 & 0.192 & $-0.150^{* * *}$ & $(-17.13)$ & 4,831 \\
Average & 0.114 & 0.263 & $-0.149 * * *$ & $(-18.34)$ & 10,325 \\
Inferior & 0.189 & 0.225 & $-0.036 * * *$ & $(-2.98)$ & 3,765 \\
\hline *** Indicates
\end{tabular}

***Indicates statistical significance at the 0.01 level. 
Table 3

Differences in forecast accuracy for actual superior analyst by industry in the pre- and post-FD periods

This table shows the mean relative and absolute forecast accuracy for analysts classified as superior prior to the implementation of Regulation FD and compares their forecast accuracy during the pre- and post-FD periods. An analyst is classified as superior/average/inferior if his relative forecast accuracy, measured by PMAFE, is in the top decile/middle 80 percentile/bottom decile of all analysts making forecasts for the same firm in the same year during the year immediately prior to regulation implementation (October 1999 to September 2000. In Panel A results are presented for relative forecast accuracy where only analysts that make forecasts in the preand post-FD periods are included. In Panel $\mathbf{B}$ results are presented for absolute forecast accuracy where only analysts that make forecasts in the pre- and post-FD periods are included. These analysts are then classified as superior, average or inferior. Post-FD results are based on analysts' forecasts during the October 2000 to September 2001 time period. The significance and the associated t-Statistic of each difference are shown as well as the number of observations in each group.

Panel A: Annual Mean PMAFE Values for Superior Analysts

\begin{tabular}{|c|c|c|c|c|c|}
\hline $\begin{array}{l}\text { Industry } \\
\text { Classification } \\
\end{array}$ & $\begin{array}{r}\text { Pre-FD } \\
\text { Mean PMAFE } \\
\end{array}$ & $\begin{array}{r}\text { Post-FD } \\
\text { Mean PMAFE } \\
\end{array}$ & $\begin{array}{r}\text { Difference in } \\
\text { Mean PMAFE }\end{array}$ & t-Stat. & $\begin{array}{r}\text { No. of Obs. } \\
\text { Observations }\end{array}$ \\
\hline 1 - Finance & -0.699 & -0.068 & $-0.631 * * *$ & $(-15.08)$ & 660 \\
\hline 2 - Health Care & -0.739 & -0.025 & $-0.714 * * *$ & $(-12.96)$ & 543 \\
\hline 3 - Consumer Non-Durables & -0.804 & 0.004 & $-0.809^{* * *}$ & $(-11.67)$ & 313 \\
\hline 4-Consumer Services & -0.689 & 0.016 & $-0.705 * * *$ & $(-21.71)$ & 1,014 \\
\hline 5 - Consumer Durables & -0.765 & -0.009 & $-0.756 * * *$ & $(-7.08)$ & 143 \\
\hline 6 - Energy & -0.842 & 0.060 & $-0.902 * * *$ & $(-15.86)$ & 386 \\
\hline 7 - Transportation & -0.688 & 0.112 & $-0.800 * * *$ & $(-8.41)$ & 128 \\
\hline 8 - Technology & -0.653 & -0.004 & $-0.648 * * *$ & $(-18.13)$ & 1,030 \\
\hline 9-Basic Industries & -0.804 & 0.023 & $-0.827 * * *$ & $(-16.19)$ & 377 \\
\hline 10 - Capital Goods & -0.701 & 0.049 & $-0.751 * * *$ & $(-12.52)$ & 316 \\
\hline 11 - Public Utilities & -0.690 & -0.039 & $-0.651 * * *$ & $(-18.54)$ & 372 \\
\hline
\end{tabular}

Panel B: Annual Mean AFE Values for Superior Analysts

\begin{tabular}{|c|c|c|c|c|c|}
\hline $\begin{array}{l}\text { Industry } \\
\text { Classification } \\
\end{array}$ & $\begin{array}{r}\text { Pre-FD } \\
\text { Mean AFE } \\
\end{array}$ & $\begin{array}{r}\text { Post-FD } \\
\text { Mean AFE } \\
\end{array}$ & $\begin{array}{r}\text { Difference in } \\
\text { Mean AFE } \\
\end{array}$ & t-Stat. & $\begin{array}{r}\text { No. of Obs. } \\
\text { Pre-FD Period } \\
\end{array}$ \\
\hline 1 - Finance & 0.061 & 0.195 & $-0.134 * * *$ & $(-3.94)$ & 660 \\
\hline 2-Health Care & 0.023 & 0.070 & $-0.047 * * *$ & $(-7.02)$ & 543 \\
\hline 3 - Consumer Non-Durables & 0.024 & 0.113 & $-0.088 * * *$ & $(-5.79)$ & 313 \\
\hline 4-Consumer Services & 0.045 & 0.174 & $-0.129 * * *$ & $(-7.02)$ & 1,014 \\
\hline 5 - Consumer Durables & 0.035 & 0.292 & $-0.258 * * *$ & $(4.00)$ & 143 \\
\hline 6 - Energy & 0.028 & 0.346 & $-0.317 * * *$ & $(-11.23)$ & 386 \\
\hline 7 - Transportation & 0.037 & 0.342 & $-0.305 * * *$ & $(-4.52)$ & 128 \\
\hline 8 - Technology & 0.035 & 0.198 & $-0.164 * * *$ & $(-6.72)$ & 1,030 \\
\hline 9 - Basic Industries & 0.035 & 0.271 & $-0.236 * * *$ & $(-9.57)$ & 377 \\
\hline 10 - Capital Goods & 0.054 & 0.160 & $-0.106 * * *$ & $(-4.69)$ & 316 \\
\hline 11 - Public Utilities & 0.050 & 0.325 & $-0.275 * * *$ & $(-3.95)$ & 372 \\
\hline
\end{tabular}

***Indicates statistical significance at the 0.01 level.

**Indicates statistical significance at the 0.05 level.

* Indicates statistical significance at the 0.10 level. 
Table 4

Differences in forecast accuracy for actual inferior analyst by industry in the pre- and post-FD periods

This table shows the mean relative and absolute forecast accuracy for analysts classified as superior prior to the implementation of Regulation FD and compares their forecast accuracy during the pre- and post-FD periods. An analyst is classified as superior/average/inferior if his relative forecast accuracy, measured by PMAFE, is in the top decile/middle 80 percentile/bottom decile of all analysts making forecasts for the same firm in the same year during the year immediately prior to regulation implementation (October 1999 to September 2000. In Panel A results are presented for relative forecast accuracy where only analysts that make forecasts in the preand post-FD periods are included. In Panel B results are presented for absolute forecast accuracy where only analysts that make forecasts in the pre- and post-FD periods are included. These analysts are then classified as superior, average or inferior. Post-FD results are based on analysts' forecasts during the October 2000 to September 2001 time period. The significance and the associated $t$-Statistic of each difference are shown as well as the number of observations in each group.

Panel A: Annual Mean PMAFE Values for Inferior Analysts

\begin{tabular}{|c|c|c|c|c|c|}
\hline $\begin{array}{l}\text { Industry } \\
\text { Classification } \\
\end{array}$ & $\begin{array}{r}\text { Pre-FD } \\
\text { Mean PMAFE } \\
\end{array}$ & $\begin{array}{r}\text { Post-FD } \\
\text { Mean PMAFE } \\
\end{array}$ & $\begin{array}{r}\text { Difference in } \\
\text { Mean PMAFE }\end{array}$ & t-Stat. & $\begin{array}{r}\text { No. of Obs. } \\
\text { Observations } \\
\end{array}$ \\
\hline 1 - Finance & 1.138 & 0.240 & $0.901 * * *$ & $(8.33)$ & 288 \\
\hline 2 - Health Care & 1.016 & 0.039 & $0.971 * * *$ & $(10.72)$ & 256 \\
\hline 3 - Consumer Non-Durables & 1.160 & 0.167 & $0.994 * * *$ & (7.48) & 140 \\
\hline 4 - Consumer Services & 0.948 & 0.137 & $0.811 * * *$ & $(10.83)$ & 536 \\
\hline 5 - Consumer Durables & 1.103 & 0.353 & $0.750 * * *$ & $(3.55)$ & 72 \\
\hline 6 - Energy & 1.601 & 0.278 & $1.323 * * *$ & $(9.69)$ & 164 \\
\hline 7 - Transportation & 0.940 & 0.123 & $0.817^{* * *}$ & $(4.51)$ & 55 \\
\hline 8 - Technology & 0.821 & 0.177 & $0.644 * * *$ & $(9.02)$ & 438 \\
\hline 9-Basic Industries & 1.592 & 0.239 & $1.353 * * *$ & $(9.13)$ & 171 \\
\hline 10 - Capital Goods & 0.763 & 0.243 & $0.520 * * *$ & (3.86) & 170 \\
\hline 11 - Public Utilities & 1.102 & 0.154 & $0.949 * * *$ & $(10.73)$ & 219 \\
\hline
\end{tabular}

Panel B: Annual Mean AFE Values for Inferior Analysts

\begin{tabular}{|c|c|c|c|c|c|}
\hline $\begin{array}{l}\text { Industry } \\
\text { Classification }\end{array}$ & $\begin{array}{r}\text { Pre-FD } \\
\text { Mean AFE } \\
\end{array}$ & $\begin{array}{r}\text { Post-FD } \\
\text { Mean AFE } \\
\end{array}$ & $\begin{array}{r}\text { Difference in } \\
\text { Mean AFE } \\
\end{array}$ & t-Stat. & $\begin{array}{r}\text { No. of Obs. } \\
\text { Pre-FD Period }\end{array}$ \\
\hline 1 - Finance & 0.224 & 0.311 & -0.086 & $(-0.99)$ & 288 \\
\hline 2 - Health Care & 0.133 & 0.078 & $0.055 * *$ & $(2.35)$ & 256 \\
\hline 3 - Consumer Non-Durables & 0.150 & 0.152 & -0.002 & $(-0.09)$ & 140 \\
\hline 4 - Consumer Services & 0.166 & 0.207 & -0.041 & $(-1.49)$ & 536 \\
\hline 5 - Consumer Durables & 0.192 & 0.286 & $-0.095 *$ & $(-1.91)$ & 73 \\
\hline 6 - Energy & 0.330 & 0.407 & -0.076 & $(-1.41)$ & 164 \\
\hline 7 - Transportation & 0.272 & 0.369 & -0.098 & $(-0.86)$ & 55 \\
\hline $8-$ Technology & 0.160 & 0.163 & -0.003 & $(-0.14)$ & 438 \\
\hline 9 - Basic Industries & 0.524 & 0.352 & $0.171 *$ & $(1.70)$ & 171 \\
\hline 10 - Capital Goods & 0.174 & 0.268 & $-0.094 *$ & $(-1.96)$ & 170 \\
\hline 11 - Public Utilities & 0.319 & 0.390 & -0.070 & $(-0.63)$ & 219 \\
\hline
\end{tabular}

$* * *$ Indicates statistical significance at the 0.01 level.

$* *$ Indicates statistical significance at the 0.05 level.

* Indicates statistical significance at the 0.10 level. 
Table 5

Differences in forecast accuracy for actual average analyst by industry in the pre- and post-FD periods

This table shows the mean relative and absolute forecast accuracy for analysts classified as superior prior to the implementation of Regulation FD and compares their forecast accuracy during the pre- and post-FD periods. An analyst is classified as superior/average/inferior if his relative forecast accuracy, measured by PMAFE, is in the top decile/middle 80 percentile/bottom decile of all analysts making forecasts for the same firm in the same year during the year immediately prior to regulation implementation (October 1999 to September 2000. In Panel A results are presented for relative forecast accuracy where only analysts that make forecasts in the preand post-FD periods are included. In Panel B results are presented for absolute forecast accuracy where only analysts that make forecasts in the pre- and post-FD periods are included. These analysts are then classified as superior, average or inferior. Post-FD results are based on analysts' forecasts during the October 2000 to September 2001 time period. The significance and the associated t-Statistic of each difference are shown as well as the number of observations in each group.

Panel A: Annual Mean PMAFE Values for Average Analysts

\begin{tabular}{lrrrrr}
\hline $\begin{array}{l}\text { Industry } \\
\text { Classification }\end{array}$ & $\begin{array}{r}\text { Pre-FD } \\
\text { Mean PMAFE }\end{array}$ & $\begin{array}{r}\text { Post-FD } \\
\text { Mean PMAFE }\end{array}$ & $\begin{array}{r}\text { Difference in } \\
\text { Mean PMAFE }\end{array}$ & $\begin{array}{r}\text { No. of Obs. } \\
\text { Observations }\end{array}$ \\
\hline 1- Finance & -0.161 & 0.020 & $-0.182 * * *$ & $(-6.48)$ & 1,517 \\
2- Health Care & -0.163 & 0.019 & $-0.183 * * *$ & $(-5.20)$ & 1,057 \\
3- Consumer Non-Durables & -0.164 & 0.002 & $-0.165 * * *$ & $(-3.54)$ & 617 \\
4- Consumer Services & -0.153 & 0.009 & $-0.162 * * *$ & $(-7.42)$ & 2,198 \\
5- Consumer Durables & -0.148 & 0.040 & $-0.188 * * *$ & $(-3.00)$ & 396 \\
6- Energy & -0.227 & 0.032 & $-0.259 * * *$ & $(-8.67)$ & 1,317 \\
7- Transportation & -0.169 & 0.021 & $-0.190 * * *$ & $(-3.02)$ & 292 \\
8- Technology & -0.175 & 0.078 & $-0.253 * * *$ & $(-10.45)$ & 2,658 \\
9- Basic Industries & -0.213 & -0.023 & $-0.190 * * *$ & $(7.15)$ & 1,319 \\
10- Capital Goods & -0.156 & -0.056 & $-0.099 * *$ & $(-2.32)$ & 634 \\
11- Public Utilities & -0.106 & -0.011 & $-0.095 * * *$ & $(-3.43)$ & 880 \\
\hline
\end{tabular}

Panel B: Annual Mean AFE Values for Average Analysts

\begin{tabular}{|c|c|c|c|c|c|}
\hline $\begin{array}{l}\text { Industry } \\
\text { Classification }\end{array}$ & $\begin{array}{r}\text { Pre-FD } \\
\text { Mean AFE }\end{array}$ & $\begin{array}{r}\text { Post-FD } \\
\text { Mean AFE }\end{array}$ & $\begin{array}{r}\text { Difference in } \\
\text { Mean AFE }\end{array}$ & t-Stat. & $\begin{array}{l}\text { No. of Obs. } \\
\text { Pre-FD Period }\end{array}$ \\
\hline 1 - Finance & 0.150 & 0.231 & $-0.080 * * *$ & $(-3.29)$ & 1,517 \\
\hline 2 - Health Care & 0.078 & 0.136 & $-0.059 * * *$ & $(-5.09)$ & 1,057 \\
\hline 3 - Consumer Non-Durables & 0.091 & 0.126 & $-0.035 * * *$ & $(-3.06)$ & 617 \\
\hline 4 - Consumer Services & 0.125 & 0.247 & $-0.122 * * *$ & $(-7.98)$ & 2,189 \\
\hline 5 - Consumer Durables & 0.128 & 0.312 & $-0.184 * * *$ & $(-5.31)$ & 396 \\
\hline 6 - Energy & 0.123 & 0.441 & $-0.318^{* * *}$ & $(-17.01)$ & 1,317 \\
\hline 7 - Transportation & 0.155 & 0.437 & $-0.282 * * *$ & $(-5.14)$ & 292 \\
\hline $8-$ Technology & 0.102 & 0.221 & $-0.151 * * *$ & $(-7.40)$ & 2,658 \\
\hline 9 - Basic Industries & 0.158 & 0.274 & $-0.116^{* * *}$ & $(-6.12)$ & 1,319 \\
\hline 10 - Capital Goods & 0.135 & 0.179 & $-0.044 *$ & $(-1.90)$ & 634 \\
\hline 11 - Public Utilities & 0.210 & 0.385 & $-0.175 * * *$ & $(-4.40)$ & 880 \\
\hline
\end{tabular}

$* * *$ Indicates statistical significance at the 0.01 level.

** Indicates statistical significance at the 0.05 level.

* Indicates statistical significance at the 0.10 level. 
Table 6

Difference in forecast accuracy for consistently superior, average, and inferior analysts: Quarterly

This table shows the mean relative (PMAFE) and absolute (AFE) forecast accuracy for analysts that are consistently superior, average or inferior prior to the implementation of Regulation FD and compares their forecast accuracy during the pre- and post-FD periods. In Panel A (PMAFE) and B (AFE), an analyst is classified as consistently superior/average/inferior if his relative forecast accuracy, measured by PMAFE, is in the top quartile/middle 50 percentile/bottom quartile of all analysts making forecasts for the same firm in the same year for every quarter in each of the four quarters immediately prior to regulation implementation. Post-FD values are calculated using analysts' forecasts for the two quarters immediately subsequent to regulation implementation. An analyst is included in the sample only if he has made a forecast for each of the six quarters. In Panel C (PMAFE) and D (AFE), an analyst is classified as consistently superior/average/inferior if his relative forecast accuracy, measured by PMAFE, is in the top quartile/middle 50 percentile/bottom quartile of all analysts making forecasts for the same firm in the same year for every quarter in each of the two quarters immediately prior to regulation implementation. Post-FD values are calculated using analysts' forecasts for the two quarters immediately subsequent to regulation implementation. An analyst is included in the sample only if he has made a forecast for each of the four quarters. Associated t-statistics and number of observations are also presented.

Panel A. PMAFE values for four-quarter consistent analysts

\begin{tabular}{|c|c|c|c|c|c|}
\hline $\begin{array}{l}\text { Analyst } \\
\text { Type } \\
\end{array}$ & $\begin{array}{r}\text { Pre-FD } \\
\text { Mean PMAFE } \\
\end{array}$ & $\begin{array}{r}\text { Post-FD } \\
\text { Mean PMAFE } \\
\end{array}$ & $\begin{array}{r}\text { Difference in } \\
\text { Mean PMAFE }\end{array}$ & t-Stat. & $\mathbf{N}$ \\
\hline Superior & -0.351 & 0.099 & $-0.450 * *$ & $(-2.16)$ & 41 \\
\hline Average & -0.070 & -0.014 & -0.056 & $(-1.20)$ & 238 \\
\hline Inferior & 0.384 & 0.107 & $0.278 *$ & (1.96) & 26 \\
\hline
\end{tabular}

Panel B. AFE values for four-quarter consistent analysts

\begin{tabular}{lrrrrr}
$\begin{array}{l}\text { Analyst } \\
\text { Type }\end{array}$ & $\begin{array}{r}\text { Pre-FD } \\
\text { Mean AFE }\end{array}$ & $\begin{array}{r}\text { Post-FD } \\
\text { Mean AFE }\end{array}$ & $\begin{array}{r}\text { Difference in } \\
\text { Mean AFE }\end{array}$ & t-Stat. & N \\
\hline Superior & 0.035 & 0.058 & $-0.023^{* *}$ & $(-2.47)$ & 43 \\
Average & 0.051 & 0.067 & $-0.016^{* * *}$ & $(-2.96)$ & 241 \\
Inferior & 0.071 & 0.061 & 0.010 & $(1.08)$ & 26 \\
\hline
\end{tabular}

Panel C. PMAFE values for two-quarter consistent analysts

\begin{tabular}{lrrrrr}
\hline $\begin{array}{l}\text { Analyst } \\
\text { Type }\end{array}$ & $\begin{array}{r}\text { Pre-FD } \\
\text { Mean PMAFE }\end{array}$ & $\begin{array}{r}\text { Post-FD } \\
\text { Mean PMAFE }\end{array}$ & $\begin{array}{c}\text { Difference in } \\
\text { Mean PMAFE }\end{array}$ & t-Stat. & N \\
\hline Superior & -0.532 & -0.071 & $-0.461 * * *$ & $(-9.19)$ & 164 \\
Average & -0.103 & -0.037 & $-0.065 * * *$ & $(-3.07)$ & 1,032 \\
Inferior & 0.891 & 0.127 & $0.764 * * *$ & $(6.10)$ & 151 \\
\hline
\end{tabular}

Panel D. AFE values for two-quarter consistent analysts

\begin{tabular}{lrrrrr}
\hline $\begin{array}{l}\text { Analyst } \\
\text { Type }\end{array}$ & $\begin{array}{r}\text { Pre-FD } \\
\text { Mean AFE }\end{array}$ & $\begin{array}{r}\text { Post-FD } \\
\text { Mean AFE }\end{array}$ & $\begin{array}{r}\text { Difference in } \\
\text { Mean AFE }\end{array}$ & t-Stat. & N \\
\hline Superior & 0.048 & 0.113 & $-0.064^{*}$ & $(-1.76)$ & 164 \\
Average & 0.061 & 0.074 & $-0.013^{* *}$ & $(-1.98)$ & 1,032 \\
Inferior & 0.099 & 0.073 & $0.026 * * *$ & $(3.35)$ & 153 \\
\hline
\end{tabular}

***Indicates statistical significance at the 0.01 level.

** Indicates statistical significance at the 0.05 level.

* Indicates statistical significance at the 0.10 level. 
Table 7

Difference in forecast accuracy for consistently superior, average, and inferior analysts: Annual

This table shows the mean relative (PMAFE) and absolute (AFE) forecast accuracy for analysts that are consistently superior, average or inferior prior to the implementation of Regulation FD and compares their forecast accuracy during the pre- and post-FD periods. Panel A presents results for relative forecast accuracy and Panel B presents results for absolute forecast accuracy. An analyst is classified as consistently superior/average/inferior if his relative forecast accuracy, measured by PMAFE, is in the top quartile/middle 50 percentile/bottom quartile of all analysts making forecasts for the same firm in the same year for every year in each of the two years immediately prior to regulation implementation. Post-FD values are calculated using analysts' forecasts for the year immediately subsequent to regulation implementation. An analyst is included in the sample only if he has made a forecast for each of the three years. Associated t-statistics and number of observations are also presented.

Panel A. PMAFE values for two-year consistent analysts

\begin{tabular}{lrrrrr}
\hline $\begin{array}{l}\text { Analyst } \\
\text { Type }\end{array}$ & $\begin{array}{r}\text { Pre-FD } \\
\text { Mean PMAFE }\end{array}$ & $\begin{array}{r}\text { Post-FD } \\
\text { Mean PMAFE }\end{array}$ & $\begin{array}{c}\text { Difference in } \\
\text { Mean PMAFE }\end{array}$ & t-Stat. & N \\
\hline Superior & -0.623 & -0.024 & $-0.599 * * *$ & $(-19.88)$ & 1,158 \\
Average & -0.228 & 0.001 & $-0.230^{* * *}$ & $(-16.50)$ & 6,304 \\
Inferior & 0.939 & 0.232 & $0.707 * * *$ & $(14.72)$ & 893 \\
\hline
\end{tabular}

Panel B. AFE values for two-year consistent analysts

\begin{tabular}{|c|c|c|c|c|c|}
\hline $\begin{array}{l}\text { Analyst } \\
\text { Type } \\
\end{array}$ & $\begin{array}{r}\text { Pre-FD } \\
\text { Mean AFE } \\
\end{array}$ & $\begin{array}{r}\text { Post-FD } \\
\text { Mean AFE } \\
\end{array}$ & $\begin{array}{r}\text { Difference in } \\
\text { Mean AFE } \\
\end{array}$ & t-Stat. & $\mathbf{N}$ \\
\hline Superior & 0.064 & 0.249 & $-0.185 * * *$ & $(-8.50)$ & 1,160 \\
\hline Average & 0.088 & 0.208 & $-0.120 * * *$ & $(-15.60)$ & 6,328 \\
\hline Inferior & 0.196 & 0.231 & $-0.035 *$ & $(-1.92)$ & 898 \\
\hline
\end{tabular}

***Indicates statistical significance at the 0.01 level.

* Indicates statistical significance at the 0.10 level. 
Table 8

Differences in absolute forecast accuracy between analyst groups during the pre- and post-FD periods

This table presents differences in absolute (AFE) forecast accuracy between superior, average and inferior analysts where an analyst is classified as superior/average/inferior if his relative forecast accuracy, measured by PMAFE, is in the top quartile/middle 50 percentile/bottom quartile of all analysts making forecasts for the same firm in the same year for every year in each of the two years immediately prior to regulation implementation. Panel A presents results for differences in AFE during the pre-FD period and Panel B presents results for differences in AFE for the same analysts during the post-FD period. Post-FD values are calculated using analysts' forecasts for the year immediately subsequent to regulation implementation. An analyst is included in the sample only if he has made a forecast for each of the three years. The number of observations $(\mathrm{N}(\mathrm{a} ; \mathrm{b}))$ are presented as the following example describes: For the first row in Panel A (Superior - Average), N(a;b) would represent the number of observations for superior and average analysts (N(superior; average)). Associated $\mathrm{t}$-statistics are presented immediately below their respective values.

Panel A. Differences in AFE pre-Regulation FD

\begin{tabular}{|c|c|c|c|c|}
\hline & Quarterly & & Annual & \\
\hline & Forecasts & $\mathbf{N}(\mathbf{a} ; \mathbf{b})$ & Forecasts & $\mathbf{N}(\mathbf{a} ; \mathbf{b})$ \\
\hline \multirow[t]{2}{*}{ Superior - Average } & -0.013 & $164 ; 1,032$ & $-0.024 * * *$ & 1,$160 ; 6,328$ \\
\hline & $(-1.34)$ & & $(-4.69)$ & \\
\hline \multirow[t]{2}{*}{ Average - Inferior } & $-0.037 * * *$ & 1,$032 ; 153$ & $-0.108 * * *$ & 6,$328 ; 898$ \\
\hline & $(-3.38)$ & & $(-13.59)$ & \\
\hline \multirow[t]{2}{*}{ Superior - Inferior } & $-0.050 * * *$ & $164 ; 153$ & $-0.132 * * *$ & 1,$160 ; 898$ \\
\hline & $(-2.94)$ & & $(-13.21)$ & \\
\hline \multicolumn{5}{|c|}{ Panel B. Differences in AFE post-Regulation FD } \\
\hline & Quarterly & & Annual & \\
\hline & Forecasts & $\mathbf{N}(\mathbf{a} ; \mathbf{b})$ & Forecasts & $\mathbf{N}(\mathbf{a} ; \mathbf{b})$ \\
\hline \multirow[t]{2}{*}{ Superior - Average } & 0.039 & $164 ; 1,032$ & $0.042 *$ & 1,$160 ; 6,328$ \\
\hline & $(0.97)$ & & $(1.77)$ & \\
\hline \multirow[t]{2}{*}{ Average - Inferior } & 0.000 & 1,$032 ; 153$ & -0.024 & 6,$328 ; 898$ \\
\hline & $(0.03)$ & & $(-1.17)$ & \\
\hline \multirow[t]{2}{*}{ Superior - Inferior } & 0.040 & $164 ; 153$ & 0.018 & 1,$160 ; 898$ \\
\hline & $(0.10)$ & & $(0.61)$ & \\
\hline
\end{tabular}

***Indicates statistical significance at the 0.01 level.

* Indicates statistical significance at the 0.10 level. 
Table 9

Regression results examining explanatory power of analyst-specific variables - Model (1)

This table presents the regression results for, in Panel A, each year in the research and, in Panel B, the pooled regression results for the entire sample. Regression coefficient values are reported with corresponding t-statistics listed immediately below in brackets. The dependant variable is the PMAFE which is equal to the difference between the absolute value of the forecast error for a particular analyst following a particular firm in a given year and the mean absolute forecast error for all analysts following that firm in that year deflated by the mean forecast error. All explanatory variables are calculated relative to other analysts following the same firm in the same year. For, example, DAGE is calculated as the forecast age of a particular analyst less the average forecast age of all other analysts following the same firm in the same year. Other explanatory variables are defined as follows: DGEXP is the analyst's general experience, i.e., the number of years the analyst has made a forecast for any company. DCEXP is the analyst's company-specific experience. DNCOS is the number of companies the analyst follows. DNSIG is the number of industries (defined as two-digit SIG codes) the analyst follows. If there is no estimate for the last period then this observation is removed from the data set.

\begin{tabular}{|c|c|c|c|c|c|c|c|}
\hline Year & DAGE & DGEXP & DCEXP & DNCOS & DNSIG & DNOANY & Adj. $R^{2}$ \\
\hline \multirow[t]{2}{*}{1984} & $0.0039 * * *$ & 0.0010 & $0.0663 * * *$ & -0.0001 & $0.0103 * *$ & $-0.0006^{* * *}$ & 0.1414 \\
\hline & $(50.12)$ & $(0.07)$ & (3.68) & $(-0.16)$ & $(2.40)$ & $(-3.32)$ & \\
\hline \multirow[t]{2}{*}{1985} & $0.0042 * * *$ & 0.0056 & $0.0299 * * *$ & -0.0005 & 0.0011 & $-0.0007 * * *$ & 0.1375 \\
\hline & $(54.310$ & $(0.60)$ & (2.78) & $(-1.08)$ & $(0.29)$ & $(-3.00)$ & \\
\hline \multirow[t]{2}{*}{1986} & $0.0017^{* * *}$ & -0.0109 & -0.0092 & -0.0008 & $0.0287 * * *$ & $-0.0014^{* * *}$ & 0.0234 \\
\hline & (19.69) & $(-1.25)$ & $(-0.93)$ & $(-1.44)$ & (5.95) & $(-7.84)$ & \\
\hline \multirow[t]{2}{*}{1987} & $0.0034 * * *$ & $0.0116 * *$ & $-0.0240 * * *$ & -0.0004 & $0.0162 * * *$ & $-0.0008 * * *$ & 0.1294 \\
\hline & $(52.84)$ & (2.32) & $(-4.21)$ & $(-0.95)$ & (4.33) & $(-3.88)$ & \\
\hline \multirow[t]{2}{*}{1988} & $0.0029 * * *$ & 0.0001 & -0.0066 & $0.0016 * * *$ & 0.0021 & $-0.0009 * * *$ & 0.0801 \\
\hline & $(40.66)$ & $(0.03)$ & $(-1.31)$ & $(4.41)$ & $(0.51)$ & $(-3.61)$ & \\
\hline \multirow[t]{2}{*}{1989} & $0.0032 * * *$ & -0.0047 & $-0.0113 * * *$ & 0.0116 & 0.0013 & $-0.0016^{* * *}$ & 0.1167 \\
\hline & $(49.68)$ & $(-1.43)$ & $(-2.88)$ & (1.20) & $(0.34)$ & $(-7.40)$ & \\
\hline \multirow[t]{2}{*}{1990} & $0.0036 * * *$ & -0.0034 & $-0.0099 * * *$ & $0.0008 *$ & 0.0049 & $-0.0023^{* * *}$ & 0.1270 \\
\hline & $(48.07)$ & $(-1.07)$ & $(-2.63)$ & (1.79) & (1.12) & $(-8.85)$ & \\
\hline \multirow[t]{2}{*}{1991} & $0.0044 * * *$ & 0.0033 & $-0.0163 * * *$ & 0.0002 & $0.0128 * * *$ & $-0.0031^{* * *}$ & 0.1556 \\
\hline & $(52.76)$ & (1.05) & $(-4.46)$ & $(0.44)$ & $(2.80)$ & $(-9.91)$ & \\
\hline \multirow[t]{2}{*}{1992} & $0.0037 * * *$ & 0.0033 & $-0.0179 * * *$ & $0.0016 * * *$ & 0.0029 & $-0.0016^{* * *}$ & 0.1002 \\
\hline & $(42.37)$ & (1.12) & $(-5.14)$ & $(4.00)$ & $(0.60)$ & $(-5.31)$ & \\
\hline 1993 & $0.0046^{* * *}$ & $-0.0078 * * *$ & -0.0042 & 0.0001 & $0.0132 * * *$ & $-0.0019 * * *$ & 0.1559 \\
\hline
\end{tabular}




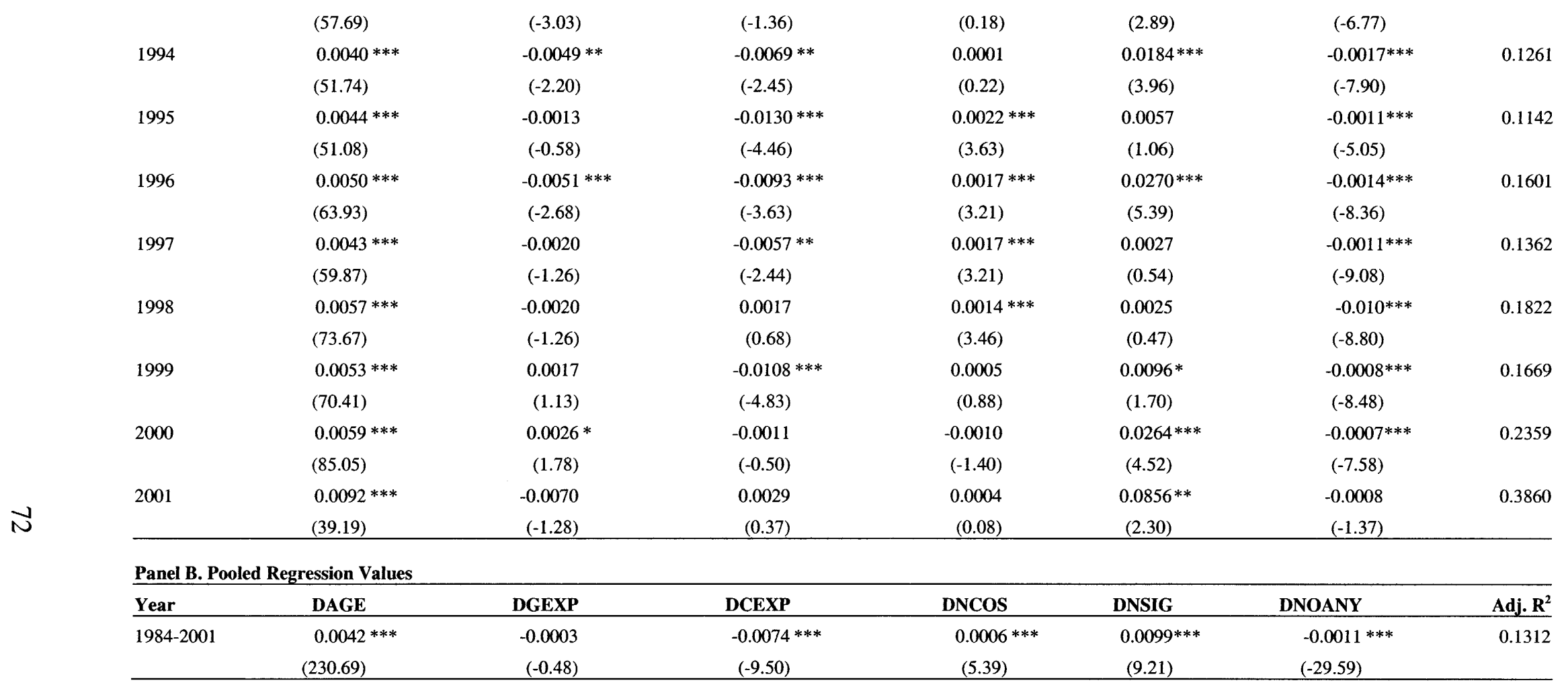


Table 10

Regression results examining explanatory power of analyst-specific variables - Model (2)

This table presents the regression results for, in Panel A, each year in the research and, in Panel B, the pooled regression results for the entire sample. Regression coefficient values are reported with corresponding t-statistics listed immediately below in brackets. The dependant variable is the PMAFE which is equal to the difference between the absolute value of the forecast error for a particular analyst following a particular firm in a given year and the mean absolute forecast error for all analysts following that firm in that year deflated by the mean forecast error. All explanatory variables are calculated relative to other analysts following the same firm in the same year. For, example, DAGE is calculated as the forecast age of a particular analyst less the average forecast age of all other analysts following the same firm in the same year. Other explanatory variables are defined as follows: LPMAFE is the PMAFE for the analyst in the immediately preceding time period. If there is no estimate for the last period then this observation is removed from the data set.

\begin{tabular}{|c|c|c|c|}
\hline Year & DAGE & LPMAFE & Adj. $R^{2}$ \\
\hline \multirow[t]{2}{*}{1984} & $0.0041 * * *$ & $0.0961 * * *$ & 0.1493 \\
\hline & $(37.49)$ & $(7.21)$ & \\
\hline \multirow[t]{2}{*}{1985} & $0.0048 * * *$ & $0.0943 * * *$ & 0.1626 \\
\hline & $(41.77)$ & $(7.05)$ & \\
\hline \multirow[t]{2}{*}{1986} & $0.0017 * * *$ & $0.1064 * * *$ & 0.0219 \\
\hline & $(14.71)$ & $(7.48)$ & \\
\hline \multirow[t]{2}{*}{1987} & $0.0035 * * *$ & $0.0118 * * *$ & 0.1385 \\
\hline & $(43.97)$ & $(1.71)$ & \\
\hline \multirow[t]{2}{*}{1988} & $0.0030 * * *$ & $0.0679 * * *$ & 0.0860 \\
\hline & $(33.20)$ & $(6.32)$ & \\
\hline \multirow[t]{2}{*}{1989} & $0.0033 * * *$ & $0.0448^{* * *}$ & 0.1187 \\
\hline & $(39.59)$ & $(4.58)$ & \\
\hline \multirow[t]{2}{*}{1990} & $0.0038 * * *$ & $0.0665 * * *$ & 0.1383 \\
\hline & $(40.96)$ & $(6.14)$ & \\
\hline \multirow[t]{2}{*}{1991} & $0.0044 * * *$ & $0.0599 * * *$ & 0.1450 \\
\hline & $(46.56)$ & $(6.14)$ & \\
\hline \multirow[t]{2}{*}{1992} & $0.0035 * * *$ & $0.0794 * * *$ & 0.0991 \\
\hline & $(37.50)$ & $(8.71)$ & \\
\hline \multirow[t]{2}{*}{1993} & $0.0049 * * *$ & $0.0763 * * *$ & 0.1448 \\
\hline & $(47.26)$ & (7.85) & \\
\hline \multirow[t]{2}{*}{1994} & $0.0039 * * *$ & $0.0104 * * *$ & 0.1251 \\
\hline & $(42.24)$ & $(10.86)$ & \\
\hline \multirow[t]{2}{*}{1995} & $0.0046 * * *$ & $0.1850 * * *$ & 0.1465 \\
\hline & $(45.21)$ & $(17.60)$ & \\
\hline \multirow[t]{2}{*}{1996} & $0.0050 * * *$ & $0.1159 * * *$ & 0.1731 \\
\hline & (53.66) & (13.88) & \\
\hline \multirow[t]{2}{*}{1997} & $0.0043 * * *$ & $0.0761 * * *$ & 0.1435 \\
\hline & (49.59) & $(8.72)$ & \\
\hline \multirow[t]{2}{*}{1998} & $0.0060 * * *$ & $0.0753 * * *$ & 0.2039 \\
\hline & $(63.52)$ & $(8.42)$ & \\
\hline \multirow[t]{2}{*}{1999} & $0.0054 * * *$ & $0.0394 * * *$ & 0.1853 \\
\hline & $(60.91)$ & $(4.63)$ & \\
\hline \multirow[t]{2}{*}{2000} & $0.0061 * * *$ & $0.0757 * * *$ & 0.2623 \\
\hline & $(43.64)$ & $(8.61)$ & \\
\hline \multirow[t]{2}{*}{2001} & $0.0095 * * *$ & $0.0564 * *$ & 0.3953 \\
\hline & $(34.33)$ & $(1.64)$ & \\
\hline \multicolumn{4}{|c|}{ Panel B. Pooled Regression Values } \\
\hline Year & DAGE & LPMAFE & Adj. $R^{2}$ \\
\hline \multirow[t]{2}{*}{ 1984-2001 } & $0.0043 * * *$ & $0.0779 * * *$ & 0.1413 \\
\hline & $(188.93)$ & $(32.70)$ & \\
\hline
\end{tabular}

***Indicates statistical significance at the 0.01 level.

* Indicates statistical significance at the 0.10 level. 
Table 11

Regression results examining explanatory power of analyst-specific variables - Model (3)

This table presents the regression results for, in Panel A, each year in the research and, in Panel B, the pooled regression results for the entire sample. Regression coefficient values are reported with corresponding t-statistics listed immediately below in brackets. The dependant variable is the PMAFE which is equal to the difference between the absolute value of the forecast error for a particular analyst following a particular firm in a given year and the mean absolute forecast error for all analysts following that firm in that year deflated by the mean forecast error. All explanatory variables are calculated relative to other analysts following the same firm in the same year. For, example, DAGE is calculated as the forecast age of a particular analyst less the average forecast age of all other analysts following the same firm in the same year. Other explanatory variables are defined as follows: DGEXP is the analyst's general experience, i.e., the number of years the analyst has made a forecast for any company. DCEXP is the analyst's company-specific experience. DNCOS is the number of companies general experience, i.e., the number of years the analyst has made a forecast for any company. DCEXP is the analyst's company-specific experience. DNCOS is the number of companies
the analyst follows. DNSIG is the number of industries (defined as two-digit SIG codes) the analyst follows. DNOANY is the number of analysts in the brokerage house for which the analyst works. DFREQ is the number of forecasts the analyst makes for a particular firm in a particular year. LPMAFE is the PMAFE for the analyst in the immediately preceding time period. If there is no estimate for the last period then this observation is removed from the data set.

\begin{tabular}{|c|c|c|c|c|c|c|c|c|c|}
\hline \multicolumn{10}{|c|}{ Panel A. Annual Regressions } \\
\hline Year & DAGE & DGEXP & DCEXP & DNCOS & DNSIG & DNOANY & DFREQ & LPMAFE & Adj. $R^{2}$ \\
\hline \multirow[t]{2}{*}{1984} & $0.0028 * * *$ & -0.0087 & $0.0674 *$ & 0.0000 & $0.0121 * *$ & -0.0004 & $-0.1224 * * *$ & $0.0878 * * *$ & 0.1537 \\
\hline & (23.10) & $(-0.41)$ & (1.76) & $(-0.03)$ & (2.07) & $(-1.27)$ & $(-16.72)$ & (8.04) & \\
\hline \multirow[t]{2}{*}{1985} & $0.0034 * * *$ & -0.0152 & 0.0159 & $-0.0022 * * *$ & -0.0076 & $-0.0008 * * *$ & $-0.1197 * * *$ & $0.0877 * * *$ & 0.1839 \\
\hline & $(29.45)$ & $(-0.96)$ & $(0.88)$ & $(-3.81)$ & $(-1.63)$ & $(-2.87)$ & $(-18.50)$ & (8.24) & \\
\hline \multirow[t]{2}{*}{1986} & $0.0014 * * *$ & $-0.0298 * * *$ & $-0.0291 * *$ & $-0.0015 * *$ & $0.0265 * * *$ & $-0.0012 * * *$ & $-0.0846^{* * *}$ & $0.0907 * * *$ & 0.0515 \\
\hline & (11.86) & $(-2.60)$ & $(-2.27)$ & $(-2.46)$ & $(5.01)$ & $(-5.89)$ & $(-11.77)$ & (7.96) & \\
\hline \multirow[t]{2}{*}{1987} & $0.0031 * * *$ & $0.0255^{* * *}$ & $-0.0333 * * *$ & $-0.0015 * * *$ & $0.0132 * * *$ & $-0.0011 * * *$ & $-0.0681 * * *$ & $0.0230 * * *$ & 0.1505 \\
\hline & (33.96) & (3.55) & $(-4.21)$ & $(-2.76)$ & (2.99) & $(-4.60)$ & $(-13.03)$ & (3.47) & \\
\hline \multirow[t]{2}{*}{1988} & $0.0025 * * *$ & -0.0024 & $-0.0165 * * *$ & 0.0008 & -0.0007 & $-0.0009 * * *$ & $-0.0735 * * *$ & $0.0430 * * *$ & 0.1052 \\
\hline & (26.64) & $(-0.42)$ & $(-2.61)$ & (1.60) & $(-0.41)$ & $(-3.37)$ & $(-14.74)$ & (4.83) & \\
\hline \multirow[t]{2}{*}{1989} & $0.0030 * * *$ & $-0.0106 * *$ & -0.0046 & 0.0003 & -0.0007 & $-0.0010^{* * *}$ & $-0.0360 * * *$ & $0.0453 * * *$ & 0.1317 \\
\hline & $(37.02)$ & $(-2.43)$ & $(-0.96)$ & $(0.62)$ & $(-0.17)$ & $(-4.33)$ & $(-8.39)$ & $(5.48)$ & \\
\hline \multirow[t]{2}{*}{1990} & $0.0038^{* * *}$ & -0.0051 & $-0.0130 * * *$ & -0.0002 & 0.0001 & $-0.0021 * * *$ & $-0.0299 * * *$ & $0.0452 * * *$ & 0.1730 \\
\hline & (42.04) & $(-1.29)$ & $(-2.89)$ & $(-0.44)$ & $(0.02)$ & $(-7.67)$ & $(-6.88)$ & $(4.95)$ & \\
\hline \multirow[t]{2}{*}{1991} & $0.0041 * * *$ & -0.0007 & $-0.0102 * * *$ & 0.0003 & 0.0027 & $-0.0023 * * *$ & $-0.0352 * * *$ & $0.0444 * * *$ & 0.1568 \\
\hline & (44.13) & $(-0.20)$ & $(-2.73)$ & $(0.67)$ & $(0.57)$ & $(-7.68)$ & $(-8.74)$ & (5.19) & \\
\hline \multirow[t]{2}{*}{1992} & $0.0034 * * *$ & -0.0008 & $-0.0083 * *$ & 0.0001 & $0.0080 *$ & $-0.0015 * * *$ & $-0.0378 * * *$ & $0.0719^{* * *}$ & 0.1240 \\
\hline & (37.83) & $(-0.27)$ & $(-2.48)$ & $(0.21)$ & (1.77) & $(-5.49)$ & $(-9.79)$ & $(9.48)$ & \\
\hline 1993 & $0.0037^{* * *}$ & $-0.0079 * * *$ & 0.0014 & 0.0002 & 0.0077 * & $-0.0018 * * *$ & $-0.0575 * * *$ & $0.0714 * * *$ & 0.1532 \\
\hline
\end{tabular}




\begin{tabular}{|c|c|c|c|c|c|c|c|c|c|}
\hline & $(41.11)$ & $(-2.82)$ & $(0.42)$ & $(0.38)$ & (1.69) & $(-6.69)$ & $(-13.32)$ & $(8.80)$ & \\
\hline \multirow[t]{2}{*}{1994} & $0.0035 * * *$ & $-0.0084 * * *$ & -0.0020 & $-0.0012 * *$ & $0.0127^{* * *}$ & $-0.0014 * * *$ & $-0.0511 * * *$ & $0.0947^{* * *}$ & 0.1419 \\
\hline & (38.45) & $(-3.31)$ & $(-0.68)$ & $(-2.34)$ & $(2.67)$ & $(-6.33)$ & $(-10.99)$ & (10.94) & \\
\hline \multirow[t]{2}{*}{1995} & $0.0041 * * *$ & -0.0014 & $-0.0054 *$ & $0.0010^{*}$ & 0.0041 & $-0.0009 * * *$ & $-0.0593 * * *$ & $0.1493 * * *$ & 0.1612 \\
\hline & $(45.71)$ & $(-0.56)$ & $(-1.77)$ & $(1.67)$ & $(0.76)$ & $(-3.95)$ & $(-11.88)$ & (16.93) & \\
\hline \multirow[t]{2}{*}{1996} & $0.0044 * * *$ & 0.0005 & $-0.0096 * * *$ & $0.0014 * *$ & $0.0170^{* * *}$ & $-0.0011 * * *$ & $-0.0654 * * *$ & $0.0930^{* * *}$ & 0.1810 \\
\hline & $(45.71)$ & $(0.25)$ & $(-3.44)$ & $(2.49)$ & $(3.21)$ & $(-6.24)$ & $(-14.19)$ & (12.63) & \\
\hline \multirow[t]{2}{*}{1997} & $0.004 * * *$ & 0.0003 & $-0.0047 *$ & 0.0001 & 0.0033 & $-0.0010 * * *$ & $-0.0592 * * *$ & $0.0731 * * *$ & 0.1684 \\
\hline & $(44.46)$ & $(0.14)$ & $(-1.92)$ & $(0.21)$ & $(0.62)$ & $(-7.27)$ & $(-13.41)$ & $(10.00)$ & \\
\hline \multirow[t]{2}{*}{1998} & $0.0051 * * *$ & -0.0005 & 0.0003 & $0.0020 * * *$ & $-0.0163 * * *$ & $-0.0008 * * *$ & $-0.0722 * * *$ & $0.0429 * * *$ & 0.221 \\
\hline & $(54.75)$ & $(-0.29)$ & $(0.13)$ & $(4.06)$ & $(-2.88)$ & $(-6.83)$ & $(-17.43)$ & $(5.69)$ & \\
\hline \multirow[t]{2}{*}{1999} & $0.0051^{* * *}$ & 0.0000 & $-0.0111 * * *$ & $0.0013 * *$ & -0.0002 & $-0.0007 * * *$ & $-0.0445 * *$ & $0.0341 * * *$ & 0.2014 \\
\hline & $(55.76)$ & $(-0.01)$ & $(-4.75)$ & $(2.09)$ & $(-0.04)$ & $(-6.99)$ & $(-10.73)$ & $(4.58)$ & \\
\hline \multirow[t]{2}{*}{2000} & $0.0054 * * *$ & $0.0029 *$ & -0.0028 & $-0.0020 * * *$ & $0.0184 * * *$ & $-0.0007 * * *$ & $-0.0553 * * *$ & $0.0539 * * *$ & 0.2674 \\
\hline & $(62.40)$ & $(1.83)$ & $(-1.24)$ & $(-2.78)$ & $(2.95)$ & $(-7.22)$ & $(-13.48)$ & $(7.23)$ & \\
\hline \multirow[t]{2}{*}{2001} & $0.0080 * * *$ & 0.0036 & $-0.0112 * * *$ & -0.0009 & 0.0092 & -0.0004 & $-0.0731 * * *$ & $0.0353 * *$ & 0.4187 \\
\hline & $(49.58)$ & $(1.27)$ & $(-2.71)$ & $(-0.34)$ & $(0.59)$ & $(-1.51)$ & $(-10.38)$ & $(2.49)$ & \\
\hline
\end{tabular}

Panel B. Pooled Regression Values

\begin{tabular}{|c|c|c|c|c|c|c|c|c|c|}
\hline Year & DAGE & DGEXP & DCEXP & DNCOS & DNSIG & DNOANY & DFREQ & LPMAFE & Adj. $R^{2}$ \\
\hline \multirow[t]{2}{*}{$1984-2001$} & $0.0039 * * *$ & -0.0003 & $-0.0069 * * *$ & 0.0002 & $0.0050 * * *$ & $-0.0011 * * *$ & $-0.0624 * * *$ & $0.0647 * * *$ & 0.1635 \\
\hline & $(-169.49)$ & $(-0.51)$ & $(-8.54)$ & $(1.27)$ & $(4.16)$ & $(-25.32)$ & $(-55.21)$ & $(32.26)$ & \\
\hline
\end{tabular}

***Indicates statistical significance at the 0.01 level

** Indicates statistical significance at the 0.05 level.

* Indicates statistical significance at the 0.10 level. 
Table 12

Correlation Matrix - Model (3)

This table presents the correlation matrix for the model 3. All explanatory variables correlations are calculated relative to all other explanatory variables for analysts following the same firm in the same year. For, example, DAGE is calculated as the forecast age of a particular analyst less the average forecast age of all other analysts following the same firm in the same year. Other explanatory variables are defined as follows: DGEXP is the analyst's general experience, i.e., the number of years the analyst has made a forecast for any company. DCEXP is the analyst's company-specific experience. DNCOS is the number of companies the analyst follows. DNSIG is the number of industries (defined as two-digit SIG codes) the analyst follows. DNOANY is the number of analysts in the brokerage house for which the analyst works. DFREQ is the number of forecasts the analyst makes for a particular firm in a particular year. LPMAFE is the PMAFE for the analyst in the immediately preceding time period. If there is no estimate for the last period then this observation is removed from the data set.

\begin{tabular}{|c|c|c|c|c|c|c|c|c|c|}
\hline Variable & Intercept & DAGE & DGEXP & DCEXP & DNCOS & DNSIG & DNOANY & DFREQ & LPMAFE \\
\hline Intercept & 1.0000 & -0.1383 & -0.0273 & -0.2102 & -0.0263 & 0.0054 & 0.0109 & -0.1654 & 0.1536 \\
\hline DAGE & -0.1383 & 1.0000 & 0.0030 & 0.0282 & 0.0610 & -0.0033 & 0.0000 & 0.5348 & -0.0106 \\
\hline DGEXP & -0.0273 & 0.0030 & 1.0000 & -0.6029 & -0.1210 & -0.0213 & -0.0683 & 0.0188 & -0.0012 \\
\hline DCEXP & -0.2102 & 0.0282 & -0.6029 & 1.0000 & -0.0131 & 0.0434 & 0.0207 & -0.0137 & 0.0026 \\
\hline DNCOS & -0.0263 & 0.0610 & -0.1210 & -0.0131 & 1.0000 & -0.4100 & 0.0679 & -0.0091 & -0.0293 \\
\hline DNSIG & 0.0054 & -0.0033 & -0.0213 & 0.0434 & -0.4100 & 1.0000 & 0.1378 & 0.0517 & -0.0100 \\
\hline DNOANY & 0.0109 & 0.0000 & -0.0683 & 0.0207 & 0.0679 & 0.1378 & 1.0000 & -0.0372 & 0.0420 \\
\hline DFREQ & -0.1654 & 0.5348 & 0.0188 & -0.0137 & -0.0091 & 0.0517 & -0.0372 & 1.0000 & 0.0460 \\
\hline LPMAFE & 0.1536 & -0.0106 & -0.0012 & 0.0026 & -0.0293 & -0.0100 & 0.0420 & 0.0460 & 1.0000 \\
\hline
\end{tabular}


Table 13

Differences in relative forecast accuracy for predicted superior and inferior analysts

This table presents the differences in forecast accuracy between predicted superior and inferior analysts for, in Panel A, each year in the research and, in Panel B, the entire sample. An analyst is predicted to be superior (inferior) if his predicted relative forecast accuracy, measured by PMAFE, is in the top (bottom) decile of all analysts making forecasts for the same firm in the same year. Predicted PMAFE is estimated for each analyst following a particular firm for a particular year using the following model: PMAFE $=a_{0}+a_{1} *$ DAGE $+a_{2} *$ DGEXP $+a_{3} *$ DCEXP $+a_{4} *$ DNCOS $+a_{5} *$ DNSIG $+a_{6} *$ DNOANY $+a_{7} *$ DFREQ $+a_{8} *$ LPMAFE where the coefficient values are calculated from the regression of the previous year (e.g. The $1994 \mathrm{a}_{0}-\mathrm{a}_{8}$ values are used for predicting 1995 analysts) and PMAFE is equal to the difference between the absolute value of the forecast error for a particular analyst following a particular firm in a given year and the mean absolute forecast error for all analysts following that firm in that year deflated by the mean forecast error. The mean of the actual PMAFE of each of these groups is then compared to see if they are significantly different from each other. The significance and the associated t-Statistic of each difference are shown as well as the number of observations in each analyst group.

Panel A. Annual Mean PMAFE Values

\begin{tabular}{lrrrrrr}
\hline & $\begin{array}{r}\text { Superior Analysts } \\
\text { Mean PMAFE }\end{array}$ & $\begin{array}{r}\text { Inferior Analysts } \\
\text { Mean PMAFE }\end{array}$ & $\begin{array}{c}\text { Difference in } \\
\text { Mean PMAFE }\end{array}$ & $\begin{array}{r}\text { No. of Obs. } \\
\text { Superior } \\
\text { Analysts }\end{array}$ & $\begin{array}{r}\text { No. of Obs. } \\
\text { Inferior } \\
\text { Analysts }\end{array}$ \\
\hline 1985 & -0.298 & 0.866 & $-1.165 * * *$ & $(-31.70)$ & 1,950 & 1,974 \\
1986 & -0.110 & 0.505 & $-0.615 * * *$ & $(-18.09)$ & 2,354 & 2,368 \\
1987 & -0.275 & 0.591 & $-0.866 * * *$ & $(-31.15)$ & 2,445 & 2,452 \\
1988 & -0.208 & 0.563 & $-0.771 * * *$ & $(-26.15)$ & 2,498 & 2,507 \\
1989 & -0.238 & 0.542 & $0.779 * * *$ & $(-30.41)$ & 2,462 & 2,478 \\
1990 & -0.221 & 0.690 & $-0.911 * * *$ & $(-30.41)$ & 2,338 & 2,361 \\
1991 & -0.226 & 0.714 & $-0.940 * * *$ & $(-30.34)$ & 2,552 & 2,571 \\
1992 & -0.222 & 0.609 & $-0.831 * * *$ & $(-28.12)$ & 2,606 & 2,617 \\
1993 & -0.253 & 0.780 & $-1.033 * * *$ & $(-33.11)$ & 2,690 & 2,703 \\
1994 & -0.277 & 0.733 & $-1.011 * * *$ & $(-34.48)$ & 2,786 & 2,805 \\
1995 & -0.288 & 0.819 & $-1.107 * * *$ & $(-33.02)$ & 2,894 & 2,922 \\
1996 & -0.293 & 0.862 & $-1.155 * * *$ & $(-35.81)$ & 3,084 & 3,115 \\
1997 & -0.249 & 0.794 & $-1.043 * * *$ & $(-36.05)$ & 3,176 & 3,199 \\
1998 & -0.284 & 0.951 & $-1.234 * * *$ & $(-40.63)$ & 3,348 & 3,387 \\
1999 & -0.260 & 0.930 & $-1.190 * * *$ & $(-39.15)$ & 3,398 & 3,426 \\
2000 -overall & -0.318 & 1.011 & $-1.329 * * *$ & $(-45.34)$ & 3,180 & 3,209 \\
2000 -preFD & -0.279 & 0.925 & $-1.205 * * *$ & $(-21.69)$ & 870 & 882 \\
2000 -postFD & -0.333 & 1.044 & $-1.376 * * *$ & $(-39.90)$ & 2,310 & 2,327 \\
2001 & -0.436 & 1.602 & $-2.038 * * *$ & $(-35.07)$ & 1,108 & 1,120 \\
\hline
\end{tabular}

Panel B. Pooled Annual Mean PMAFE Values

\begin{tabular}{lrrrrrr}
\hline Year & $\begin{array}{r}\text { Superior Analysts } \\
\text { Mean PMAFE }\end{array}$ & $\begin{array}{r}\text { Inferior Analysts } \\
\text { Mean PMAFE }\end{array}$ & $\begin{array}{r}\text { Difference in } \\
\text { Mean PMAFE }\end{array}$ & $\begin{array}{r}\text { No. of Obs. } \\
\text { Superior } \\
\text { Analysts }\end{array}$ & $\begin{array}{r}\text { No. of Obs. } \\
\text { Inferior } \\
\text { Analysts }\end{array}$ \\
\hline $1985-2001$ & -0.258 & 0.783 & $-1.041 * * *$ & $(-134.95)$ & 31,114 & 31,301 \\
\hline$* * * 14$
\end{tabular}


Table 14

Differences in relative forecast accuracy for predicted superior and average analysts

This table presents the differences in forecast accuracy between predicted superior and average analysts for, in Panel A, each year in the research and, in Panel B, the entire sample. An analyst is predicted to be superior (average) if his predicted relative forecast accuracy, measured by PMAFE, is in the top decile (middle 80 percentile) of all analysts making forecasts for the same firm in the same year. Predicted PMAFE is estimated for each analyst following a particular firm for a particular year using the following model: PMAFE $=a_{0}+a_{1} *$ DAGE $+a_{2} *$ DGEXP $+a_{3} *$ DCEXP $+a_{4} *$ DNCOS $+a_{5} *$ DNSIG $+a_{6} *$ DNOANY $+a_{7} *$ DFREQ + $a_{8} *$ LPMAFE where the coefficient values are calculated from the regression of the previous year (e.g. The $1994 a_{0}-a_{8}$ values are used for predicting 1995 analysts) and PMAFE is equal to the difference between the absolute value of the forecast error for a particular analyst following a particular firm in a given year and the mean absolute forecast error for all analysts following that firm in that year deflated by the mean forecast error. The mean of the actual PMAFE of each of these groups is then compared to see if they are significantly different from each other. The significance and the associated t-Statistic of each difference are shown as well as the number of observations in each analyst group.

Panel A. Annual Mean PMAFE Values

\begin{tabular}{lrrrrrr}
\hline & $\begin{array}{r}\text { Superior Analysts } \\
\text { Mean PMAFE }\end{array}$ & $\begin{array}{r}\text { Average Analysts } \\
\text { Mean PMAFE }\end{array}$ & $\begin{array}{c}\text { Difference in } \\
\text { Mean PMAFE }\end{array}$ & $\begin{array}{r}\text { No. of Obs. } \\
\text { Superior } \\
\text { Analysts }\end{array}$ & $\begin{array}{r}\text { No. of Obs. } \\
\text { Average } \\
\text { Analysts }\end{array}$ \\
\hline 1985 & -0.298 & -0.076 & $-0.222^{* * *}$ & $(-13.46)$ & 1,950 & 9,739 \\
1986 & -0.110 & -0.055 & $-0.055^{* *}$ & $(-2.11)$ & 2,354 & 11,986 \\
1987 & -0.275 & -0.048 & $-0.228 * * *$ & $(-16.07)$ & 2,445 & 12,126 \\
1988 & -0.208 & -0.053 & $-0.155 * * *$ & $(-10.11)$ & 2,498 & 12,265 \\
1989 & -0.238 & -0.058 & $-0.180 * * *$ & $(-13.71)$ & 2,462 & 12,266 \\
1990 & -0.221 & -0.087 & $-0.135 * * *$ & $(-8.44)$ & 2,338 & 10,901 \\
1991 & -0.226 & -0.121 & $-0.105 * * *$ & $(-6.70)$ & 2,552 & 13,091 \\
1992 & -0.222 & -0.097 & $-0.125 * * *$ & $(-8.64)$ & 2,606 & 13,791 \\
1993 & -0.253 & -0.124 & $-0.129 * * *$ & $(9.49)$ & 2,690 & 14,047 \\
1994 & -0.277 & -0.092 & $-0.185 * * *$ & $(-12.71)$ & 2,786 & 13,835 \\
1995 & -0.288 & -0.108 & $-0.180 * * *$ & $(-11.01)$ & 2,894 & 13,926 \\
1996 & -0.293 & -0.125 & $-0.168 * * *$ & $(-11.47)$ & 3,084 & 14,712 \\
1997 & -0.249 & -0.110 & $-0.140 * * *$ & $(10.33)$ & 3,176 & 14,989 \\
1998 & -0.284 & -0.132 & $-0.152 * * *$ & $(-10.83)$ & 3,348 & 15,631 \\
1999 & -0.260 & -0.116 & $-0.144 * * *$ & $(-10.99)$ & 3,398 & 16,001 \\
2000 -overall & -0.343 & -0.118 & $-0.213 * * *$ & $(-15.13)$ & 3,180 & 15,199 \\
2000 -preFD & -0.279 & -0.113 & $-0.166 * * *$ & $(-6.17)$ & 870 & 4,043 \\
2000 -postFD & -0.333 & -0.118 & $-0.194 * * *$ & $(-13.95)$ & 2,310 & 11,156 \\
2001 & -0.436 & -0.167 & $-0.270 * * *$ & $(-12.83)$ & 1,108 & 5,373 \\
\hline & & & & & &
\end{tabular}

Panel B. Pooled Annual Mean PMAFE Values

\begin{tabular}{lrrrrrr}
\hline Year & $\begin{array}{r}\text { Superior Analysts } \\
\text { Mean PMAFE }\end{array}$ & $\begin{array}{r}\text { Average Analysts } \\
\text { Mean PMAFE }\end{array}$ & $\begin{array}{c}\text { Difference in } \\
\text { Mean PMAFE }\end{array}$ & $\begin{array}{r}\text { No. of Obs. } \\
\text { Superior } \\
\text { Analysts }\end{array}$ & $\begin{array}{r}\text { No. of Obs. } \\
\text { Average } \\
\text { Analysts }\end{array}$ \\
\hline $1985-2001$ & -0.258 & -0.098 & $-0.1601 * * *$ & $(-42.33)$ & 44,869 & 219,878 \\
\hline
\end{tabular}

***Indicates statistical significance at the 0.01 level.

** Indicates statistical significance at the 0.05 level. 
Table 15

Differences in relative forecast accuracy for predicted average and inferior analysts

This table presents the differences in forecast accuracy between predicted average and inferior analysts for, in Panel A, each year in the research and, in Panel B, the entire sample. An analyst is predicted to be average (inferior) if his predicted relative forecast accuracy, measured by PMAFE, is in the middle 80 percentile (bottom decile) of all analysts making forecasts for the same firm in the same year. Predicted PMAFE is estimated for each analyst following a particular firm for a particular year using the following model: PMAFE $=a_{0}+a_{1} *$ DAGE $+a_{2} *$ DGEXP $+a_{3} *$ DCEXP $+a_{4} *$ DNCOS $+a_{5} *$ DNSIG $+a_{6} *$ DNOANY $+a_{7} *$ DFREQ $+a_{8} *$ LPMAFE where the coefficient values are calculated from the regression of the previous year (e.g. The $1994 \mathrm{a}_{0}-\mathrm{a}_{8}$ values are used for predicting 1995 analysts) and PMAFE is equal to the difference between the absolute value of the forecast error for a particular analyst following a particular firm in a given year and the mean absolute forecast error for all analysts following that firm in that year deflated by the mean forecast error. The mean of the actual PMAFE of each of these groups is then compared to see if they are significantly different from each other. The significance and the associated $t$-Statistic of each difference are shown as well as the number of observations in each analyst group.

Panel A. Annual Mean PMAFE Values

\begin{tabular}{|c|c|c|c|c|c|c|}
\hline Year & $\begin{array}{r}\text { Average Analysts } \\
\text { Mean PMAFE } \\
\end{array}$ & $\begin{array}{r}\text { Inferior Analysts } \\
\text { Mean PMAFE } \\
\end{array}$ & $\begin{array}{r}\text { Difference in } \\
\text { Mean PMAFE }\end{array}$ & t-Stat. & $\begin{array}{r}\text { No. of Obs. } \\
\text { Average } \\
\text { Analysts } \\
\end{array}$ & $\begin{array}{r}\text { No. of Obs. } \\
\text { Inferior } \\
\text { Analysts } \\
\end{array}$ \\
\hline 1985 & -0.076 & 0.866 & $-0.943 * * *$ & $(-26.93)$ & 9,739 & 1,974 \\
\hline 1986 & -0.055 & 0.505 & $-0.560 * * *$ & $(-22.09)$ & 11,986 & 2,368 \\
\hline 1987 & -0.048 & -0.591 & $-0.638 * * *$ & $(-24.36)$ & 12,126 & 2,452 \\
\hline 1988 & -0.053 & 0.563 & $-0.616 * * *$ & $(-22.73)$ & 12,265 & 2,507 \\
\hline 1989 & -0.058 & 0.542 & $-0.599 * * *$ & $(-25.01)$ & 12,266 & 2,478 \\
\hline 1990 & -0.087 & 0.690 & $-0.776 * * *$ & $(-28.53)$ & 10,901 & 2,361 \\
\hline 1991 & -0.121 & 0.660 & $-0.872 * * *$ & $(-29.56)$ & 13,091 & 2,571 \\
\hline 1992 & -0.097 & 0.609 & $-0.707 * * *$ & $(-25.99)$ & 13,791 & 2,617 \\
\hline 1993 & -0.124 & 0.780 & $-0.904 * * *$ & $(-30.69)$ & 14,047 & 2,703 \\
\hline 1994 & -0.092 & 0.733 & $-0.826 * * *$ & $(-30.33)$ & 13,835 & 2,805 \\
\hline 1995 & -0.108 & 0.819 & $-0.926 * * *$ & $(-29.97)$ & 13,926 & 2,922 \\
\hline 1996 & -0.125 & 0.862 & $-0.988 * * *$ & $(-32.53)$ & 14,712 & 3,115 \\
\hline 1997 & -0.110 & 0.794 & $-0.903 * * *$ & $(-33.25)$ & 14,989 & 3,199 \\
\hline 1998 & -0.132 & 0.951 & $-1.083 * * *$ & $(-37.95)$ & 15,631 & 3,387 \\
\hline 1999 & -0.116 & 0.930 & $-1.045 * * *$ & $(-36.45)$ & 16,001 & 3,426 \\
\hline 2000-overall & -0.105 & 1.011 & $-1.117 * * *$ & $(-40.93)$ & 15,199 & 3,209 \\
\hline 2000-preFD & -0.113 & 0.925 & $-1.039 * * *$ & $(-20.28)$ & 4,043 & 882 \\
\hline 2000-postFD & -0.103 & 1.044 & $-1.146 * * *$ & $(-35.60)$ & 11,156 & 2,327 \\
\hline 2001 & -0.167 & 1.602 & $-1.769 * * *$ & $(-31.14)$ & 5,373 & 1,120 \\
\hline
\end{tabular}

Panel B. Pooled Annualo Mean PMAFE Values

\begin{tabular}{|c|c|c|c|c|c|c|}
\hline Year & $\begin{array}{r}\text { Average Analysts } \\
\text { Mean PMAFE } \\
\end{array}$ & $\begin{array}{r}\text { Inferior Analysts } \\
\text { Mean PMAFE }\end{array}$ & $\begin{array}{r}\text { Difference in } \\
\text { Mean PMAFE }\end{array}$ & t-Stat. & $\begin{array}{r}\text { No. of Obs. } \\
\text { Average } \\
\text { Analysts } \\
\end{array}$ & $\begin{array}{r}\text { No. of Obs. } \\
\text { Inferior } \\
\text { Analysts } \\
\end{array}$ \\
\hline $1985-2001$ & -0.098 & 0.783 & $-0.8810 * * *$ & $(-123.31)$ & 219,878 & 45,214 \\
\hline
\end{tabular}


Table 16

Regression results examining explanatory power of analyst-specific variables including an FD dummy variable

This table presents the regression results for each of the predicted analyst groups, superior, inferior and average. An analyst is predicted to be superior/average/inferior if his predicted relative forecast accuracy, measured by PMAFE, is in the top decile/middle 80 percentile/bottom decile of all analysts making forecasts for the same firm in the same year. Predicted PMAFE is estimated for each analyst following a particular firm for a particular year using the following model: PMAFE $=a_{0}+a_{1} * D A G E+a_{2} *$ DGEXP $+a_{3} *$ DCEXP $+a_{4} * D N C O S+a_{5} * D N S I G+a_{6} * D N O A N Y+$ $a_{7} *$ DFREQ $+a_{8} *$ LPMAFE where the coefficient values are calculated from the regression of the previous year (e.g. The $1994 \mathrm{a}_{0}-\mathrm{a}_{8}$ values are used for predicting 1995 analysts) and PMAFE is equal to the difference between the absolute value of the forecast error for a particular analyst following a particular firm in a given year and the mean absolute forecast error for all analysts following equal to the difference between the absolute value of the forecast error for a particular analyst following a particular firm in a given year and the mean absolute forecast error for all analysts following
that firm in that year deflated by the mean forecast error. Regression coefficient values are reported with corresponding t-statistics listed immediately below in brackets. The dependant variable is the PMAFE which is equal to the difference between the absolute value of the forecast error for a particular analyst following a particular firm in a given year and the mean absolute forecast error for all analysts following that firm in that year deflated by the mean forecast error. All explanatory variables are calculated relative to other analysts following the same firm in the same year. For, example, DAGE is calculated as the forecast age of a particular analyst less the average forecast age of all other analysts following the same firm in the same year. Other explanatory variables are defined as follows: DGEXP is the analyst's general experience, i.e., the number of years the analyst has made a forecast for any company. DCEXP is the analyst's company-specific experience. DNCOS is the number of companies the analyst follows. DNSIG is the number of industries (defined as two-digit SIG codes) the analyst follows. DNOANY is the number of analysts in the brokerage house for which the analyst works. DFREQ is the number of forecasts the analyst makes for a particular firm in a particular year. LPMAFE is the PMAFE for the analyst in the immediately preceding time period. If there is no estimate for the last period then this observation is removed from the data set. PostFD is equal to 1 for fiscal year ends after October of 2000 and 0 otherwise.

\begin{tabular}{|c|c|c|c|c|c|c|c|c|c|c|c|}
\hline $\begin{array}{l}\text { Analyst } \\
\text { Type }\end{array}$ & DAGE & DGEXP & DCEXP & DNCOS & DNSIG & DNOANY & DFREQ & LPMAFE & PostFD & Adj. $R^{2}$ & $\mathbf{N}$ \\
\hline Superior & $\begin{array}{r}0.0001 \\
(0.89)\end{array}$ & $\begin{array}{r}-0.0018 \\
(-1.40)\end{array}$ & $\begin{array}{c}-0.0031 * \\
(-1.83)\end{array}$ & $\begin{array}{c}0.0008 * * * \\
(2.64)\end{array}$ & $\begin{array}{r}0.0047 \\
(1.59)\end{array}$ & $\begin{array}{l}-0.0007^{* * *} \\
(-10.07)\end{array}$ & $\begin{array}{l}-0.0305^{* * *} \\
(-15.49)\end{array}$ & $\begin{array}{c}-0.0621 * * * \\
(9.38)\end{array}$ & $\begin{array}{l}-0.1044 * * * \\
(-8.20)\end{array}$ & 0.0110 & 44,869 \\
\hline Inferior & $\begin{array}{l}0.0041 * * * \\
(38.39)\end{array}$ & $\begin{array}{r}0.0025 \\
(1.04)\end{array}$ & $\begin{array}{c}-0.0064 * \\
(-1.92)\end{array}$ & $\begin{array}{c}-0.0013 * * \\
(-2.57)\end{array}$ & $\begin{array}{r}0.0001 \\
(0.02)\end{array}$ & $\begin{array}{l}-0.0014 * * * \\
(-7.17)\end{array}$ & $\begin{array}{l}-0.3153^{* * *} \\
(-47.24)\end{array}$ & $\begin{array}{l}0.0763 * * * \\
(13.47)\end{array}$ & $\begin{array}{l}0.3355^{* * *} \\
(13.73)\end{array}$ & 0.1368 & 45,214 \\
\hline Average & $\begin{array}{r}0.003 * * * \\
(102.82) \\
\end{array}$ & $\begin{array}{r}-0.0010 \\
(-1.50) \\
\end{array}$ & $\begin{array}{l}-0.0060 * * * \\
(-7.23)\end{array}$ & $\begin{array}{l}0.0006^{* * *} \\
(4.49)\end{array}$ & $\begin{array}{l}0.0064 * * * \\
(5.03)\end{array}$ & $\begin{array}{l}-0.0010^{* * *} \\
(-21.85)\end{array}$ & $\begin{array}{l}-0.0564 * * * \\
(-42.84)\end{array}$ & $\begin{array}{l}0.0615^{* * *} \\
(27.11)\end{array}$ & $\begin{array}{l}-0.0337 * * * \\
(-5.41)\end{array}$ & 0.0757 & $\begin{array}{r}219,87 \\
8\end{array}$ \\
\hline
\end{tabular}

***Indicates statistical significance at the 0.01 level.

* Indicates statistical significance at the 0.05 level.

* Indicates statistical significance at the 0.10 level. 
Table 17

Differences in relative forecast accuracy for predicted analyst groups in the pre- and post-FD periods

This table presents the differences in relative forecast accuracy in the pre- and post-FD periods for the predicted superior, average and inferior analysts. Panel A presents results using annual earnings forecasts and Panel B presents results using quarterly earnings forecasts. An analyst is predicted to be superior/average/inferior if his predicted relative forecast accuracy, measured by PMAFE, is in the top decile/middle 80 percentile/bottom decile of all analysts making forecasts for the same firm in the same year (quarter). Predicted PMAFE is estimated for each analyst following a particular firm for a particular year using the following model: PMAFE $=a_{0}+a_{1} * D A G E+$ $a_{2} *$ DGEXP $+a_{3} *$ DCEXP $+a_{4} *$ DNCOS $+a_{5} *$ DNSIG $+a_{6} *$ DNOANY $+a_{7} *$ DFREQ $+a_{8} *$ LPMAFE where the coefficient values are calculated from the regression of the previous year (e.g. The $1994 \mathrm{a}_{0}-\mathrm{a}_{8}$ values are used for predicting 1995 analysts) and PMAFE is equal to the difference between the absolute value of the forecast error for a particular analyst following a particular firm in a given year and the mean absolute forecast error for all analysts following that firm in that year deflated by the mean forecast error. The mean of the actual PMAFE of each of these predicted analyst groups is compared during the pre- and post-FD periods to see if they are significantly different from each other. I use three pre-FD period definitions: For the annual analysis, I use (i) the entire sample, (ii) 1993 - 1998, as I/B/E/S has stated that data from 1993 is more reliable and because there has been anecdotal evidence that some firms implemented Regulation FD early, (iii) the most recent two-year period immediately prior to Regulation FD. For the quarterly analysis, I use (i) 1993 - 2000, which represents a sufficiently large, reliable sample, (ii) 1993 - 1998, for the same reason as above, (iii) the most recent five-quarter period immediately prior to Regulation FD. The significance and the associated t-Statistic of each difference are shown as well as the number of observations in each group.

Panel A. Annual Mean PMAFE Values

\begin{tabular}{|c|c|c|c|c|c|c|c|}
\hline $\begin{array}{l}\text { Pre-FD Period } \\
\text { Definition }\end{array}$ & $\begin{array}{l}\text { Analyst } \\
\text { Type }\end{array}$ & $\begin{array}{r}\text { Pre-FD } \\
\text { Mean PMAFE } \\
\end{array}$ & $\begin{array}{r}\text { Post-FD } \\
\text { Mean PMAFE } \\
\end{array}$ & $\begin{array}{r}\text { Difference in } \\
\text { Mean PMAFE }\end{array}$ & t-Stat. & $\begin{array}{r}\text { No. of Obs. } \\
\text { Pre-FD Period }\end{array}$ & $\begin{array}{r}\text { No. of Obs. } \\
\text { Post-FD Period } \\
\end{array}$ \\
\hline \multirow[t]{3}{*}{1985 -Oct. 2000} & Superior & -0.250 & -0.366 & $0.117 * * *$ & $(9.81)$ & 41,451 & 3,418 \\
\hline & Inferior & 0.746 & 1.225 & $-0.479 * * *$ & $(-16.51)$ & 28,770 & 3,447 \\
\hline & Average & -0.096 & -0.123 & $0.027 * * *$ & $(4.02)$ & 203,349 & 16,529 \\
\hline \multirow[t]{3}{*}{$1993-1998$} & Superior & -0.277 & -0.366 & $0.089 * * *$ & (7.09) & 17,194 & 3,418 \\
\hline & Inferior & 0.833 & 1.225 & $-0.392 * * *$ & $(-12.86)$ & 17,344 & 3,447 \\
\hline & Average & -0.116 & -0.123 & 0.008 & $(1.12)$ & 83,239 & 16,529 \\
\hline \multirow[t]{3}{*}{ 1999-Oct.2000 } & Superior & -0.274 & -0.366 & $0.092 * * *$ & $(6.47)$ & 6,692 & 3,418 \\
\hline & Inferior & 0.945 & 1.225 & $-0.280 * * *$ & $(-8.20)$ & 6,756 & 3,447 \\
\hline & Average & -0.121 & -0.123 & 0.003 & $(0.35)$ & 31,427 & 16,529 \\
\hline \multicolumn{8}{|c|}{ Panel B. Quarterly Mean PMAFE Values } \\
\hline $\begin{array}{l}\text { Pre-FD Period } \\
\text { Definition } \\
\end{array}$ & $\begin{array}{l}\text { Analyst } \\
\text { Type } \\
\end{array}$ & $\begin{array}{r}\text { Pre-FD } \\
\text { Mean PMAFE } \\
\end{array}$ & $\begin{array}{r}\text { Post-FD } \\
\text { Mean PMAFE } \\
\end{array}$ & $\begin{array}{r}\text { Difference in } \\
\text { Mean PMAFE } \\
\end{array}$ & t-Stat. & $\begin{array}{r}\text { No. of Obs. } \\
\text { Pre-FD Period }\end{array}$ & $\begin{array}{r}\text { No. of Obs. } \\
\text { Post-FD Period } \\
\end{array}$ \\
\hline \multirow[t]{3}{*}{ Jun. 1993-Oct. 2000} & Superior & -0.092 & -0.071 & $-0.021 *$ & $(-1.70)$ & 26,622 & 5,014 \\
\hline & Inferior & 0.138 & 0.253 & $-0.115 * * *$ & $(-6.68)$ & 26,792 & 5,044 \\
\hline & Average & -0.018 & -0.050 & $0.0314 * * *$ & $(5.56)$ & 116,039 & 22,697 \\
\hline \multirow[t]{3}{*}{ Jun. 1993-1998 } & Superior & -0.0900 & -0.071 & -0.019 & $(-1.48)$ & 18,296 & 5,014 \\
\hline & Inferior & 0.134 & 0.253 & $-0.119 * * *$ & $(-6.77)$ & 18,404 & 5,044 \\
\hline & Average & -0.017 & -0.050 & $0.033 * * *$ & $(5.63)$ & 79,040 & 22,697 \\
\hline \multirow[t]{3}{*}{ Jul. 1999-Oct.2000 } & Superior & -0.100 & -0.071 & $-0.029 *$ & $(-1.92)$ & 6,011 & 5,014 \\
\hline & Inferior & 0.153 & 0.253 & $-0.100 * * *$ & $(-4.88)$ & 6,049 & 5,044 \\
\hline & Average & -0.022 & -0.050 & $0.028 * * *$ & $(3.95)$ & 26,710 & 22,697 \\
\hline
\end{tabular}

***Indicates statistical significance at the 0.01 level

* Indicates statistical significance at the 0.10 level. 
Table 18

Differences in absolute forecast accuracy for predicted analyst groups in the pre- and post-FD periods

This table presents the differences in absolute forecast accuracy in the pre- and post-FD periods for the predicted superior, average and inferior analysts. Panel A presents results using annual earnings forecasts and Panel B presents results using quarterly earnings forecasts. An analyst is predicted to be superior/average/inferior if his predicted relative forecast accuracy, measured by PMAFE, is in the top decile/middle 80 percentile/bottom decile of all analysts making forecasts for the same firm in the same year. Predicted PMAFE is estimated for each analyst following a particular firm for a particular year using the following model: PMAFE $=a_{0}+a_{1} * D A G E+$ $a_{2} *$ DGEXP $+a_{3} *$ DCEXP $+a_{4} *$ DNCOS $+a_{5} *$ DNSIG $+a_{6} *$ DNOANY $+a_{7} *$ DFREQ $+a_{8} *$ LPMAFE where the coefficient values are calculated from the regression of the previous year (e.g. The $1994 \mathrm{a}_{0}-\mathrm{a}_{8}$ values are used for predicting 1995 analysts) and PMAFE is equal to the difference between the absolute value of the forecast error for a particular analyst following a particular firm in a given year and the mean absolute forecast error for all analysts following that firm in that year deflated by the mean forecast error. The mean of the actual absolute forecast error (AFE) of each of these predicted analyst groups is compared during the pre- and post-FD periods to see if they are significantly different from each other. I use three pre-FD period definitions: For the annual analysis, I use (i) the entire sample, (ii) 1993 1998, as $\mathrm{I} / \mathrm{B} / \mathrm{E} / \mathrm{S}$ has stated that data from 1993 is more reliable and because there has been anecdotal evidence that some firms implemented Regulation FD early, (iii) the most recent two-year period immediately prior to Regulation FD. For the quarterly analysis, I use (i) 1993 - 2000, which represents a sufficiently large, reliable sample, (ii) 1993 - 1998, for the same reason as above, (iii) the most recent five-quarter period immediately prior to Regulation FD. The significance and the associated t-Statistic of each difference are shown as well as the number of observations in each group.

Panel A. Annual Mean AFE Values

\begin{tabular}{|c|c|c|c|c|c|c|c|}
\hline $\begin{array}{l}\text { Pre-FD Period } \\
\text { Definition }\end{array}$ & $\begin{array}{l}\text { Analyst } \\
\text { Type } \\
\end{array}$ & $\begin{array}{r}\text { Pre-FD } \\
\text { Mean AFE } \\
\end{array}$ & $\begin{array}{r}\text { Post-FD } \\
\text { Mean AFE } \\
\end{array}$ & $\begin{array}{r}\text { Difference in } \\
\text { Mean AFE } \\
\end{array}$ & t-Stat. & $\begin{array}{r}\text { No. of Obs. } \\
\text { Pre-FD Period } \\
\end{array}$ & $\begin{array}{r}\text { No. of Obs } \\
\text { Post-FD Period } \\
\end{array}$ \\
\hline \multirow[t]{3}{*}{ 1985-Oct. 2000} & Superior & 0.579 & 0.203 & $0.376 * * *$ & $(4.22)$ & 41,458 & 3,421 \\
\hline & Inferior & 0.818 & 0.536 & $0.282 * * *$ & $(2.99)$ & 41,774 & 345 \\
\hline & Average & 0.608 & 0.265 & $0.343 * * *$ & $(5.05)$ & 203,352 & 16,532 \\
\hline \multirow[t]{3}{*}{ 1993-1998 } & Superior & 0.137 & 0.203 & -0.066 & $(-1.23)$ & 17,198 & 3,421 \\
\hline & Inferior & 0.323 & 0.536 & $-0.213 * * *$ & $(-3.34)$ & 17,348 & 3,450 \\
\hline & Average & 0.162 & 0.265 & $-0.104 *$ & $(-1.73)$ & 83,249 & 16,532 \\
\hline \multirow[t]{3}{*}{ July $1999-O c t .2000$} & Superior & 0.147 & 0.203 & -0.056 & $(-1.06)$ & 6,692 & 3,421 \\
\hline & Inferior & 0.358 & 0.536 & $-0.179 * * *$ & $(-2.80)$ & 6,756 & 3,450 \\
\hline & Average & 0.167 & 0.265 & -0.098 & $(-1.63)$ & 31,427 & 16,532 \\
\hline
\end{tabular}

Panel B. Quarterly Mean AFE Values

\begin{tabular}{|c|c|c|c|c|c|c|c|}
\hline $\begin{array}{l}\text { Pre-FD Period } \\
\text { Definition } \\
\end{array}$ & $\begin{array}{l}\text { Analyst } \\
\text { Type }\end{array}$ & $\begin{array}{r}\text { Pre-FD } \\
\text { Mean AFE } \\
\end{array}$ & $\begin{array}{r}\text { Post-FD } \\
\text { Mean AFE } \\
\end{array}$ & $\begin{array}{r}\text { Difference in } \\
\text { Mean AFE }\end{array}$ & t-Stat. & $\begin{array}{r}\text { No. of Obs. } \\
\text { Pre-FD Period }\end{array}$ & $\begin{array}{r}\text { No. of Obs. } \\
\text { Post-FD Period } \\
\end{array}$ \\
\hline \multirow[t]{3}{*}{ Jun. 1993-Oct. 2000} & Superior & 0.063 & 0.069 & -0.006 & $(-1.11)$ & 26,744 & 5,038 \\
\hline & Inferior & 0.082 & 0.104 & $-0.022 * * *$ & $(-3.34)$ & 26,916 & 5,069 \\
\hline & Average & 0.069 & 0.081 & $-0.012 * * *$ & $(-4.67)$ & 115,939 & 22,781 \\
\hline \multirow[t]{3}{*}{ Jun. 1993-1998 } & Superior & 0.065 & 0.069 & -0.004 & $(-0.61)$ & 18,372 & 5,038 \\
\hline & Inferior & 0.084 & 0.104 & $-0.020 * * *$ & $(-2.63)$ & 18,482 & 5,069 \\
\hline & Average & 0.071 & 0.081 & $-0.010 * * *$ & $(-3.44)$ & 79,252 & 22,781 \\
\hline \multirow[t]{3}{*}{ Jul. 1999-Oct.2000 } & Superior & 0.061 & 0.069 & $-0.008 *$ & $(-1.85)$ & 6,041 & 5,038 \\
\hline & Inferior & 0.080 & 0.104 & $-0.024 * * *$ & $(-3.99)$ & 6,079 & 5,069 \\
\hline & Average & 0.067 & 0.081 & $-0.014 * * *$ & $(-5.71)$ & 26,788 & 22,781 \\
\hline
\end{tabular}

***Indicates statistical significance at the 0.01 level.

* Indicates statistical significance at the 0.10 level 
Figure 1

Chart of differences in absolute forecast accuracy of analysts over time

This chart presents the absolute (AFE) forecast accuracy for all analysts for each year in the research. The mean average of the AFE is then plotted against time.

\section{AFE for all Analysts' Over Time}

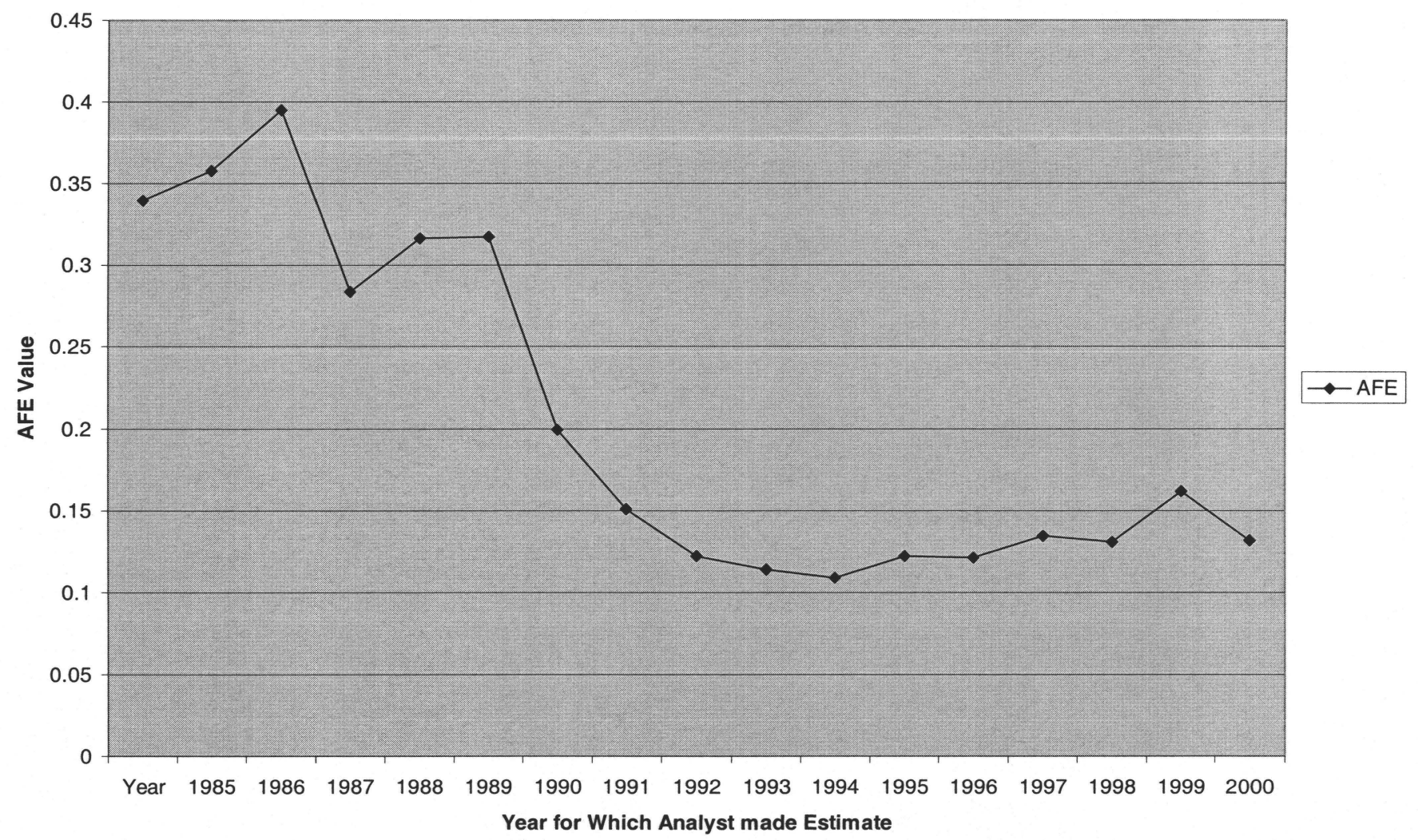


Appendix 1 - Durbin-Watson Statistic Description

The Durbin-Watson Statistic is used to test the residuals, of a regression equation, for the presence of presence of first order auto-correlation. The test develops a statistical measure of the significance of the correlation between successive time periods. The formula for the statistic is:

$$
d=\frac{\sum_{t=2}^{n}\left(e_{t}-e_{t-1}\right)^{2}}{\sum_{t=1}^{n}\left(e^{2}\right)}
$$

Where: $d=$ Durbin-Watson Statistic

$\mathrm{e}=\operatorname{residual}\left(\mathrm{Y}_{\mathrm{i}}-\mathrm{Y}_{\mathrm{c}}\right)$

$\mathrm{t}=$ time period counter

The Durbin Watson statistic is used to test for both negative and positive correlation in the residuals. The Durbin-Watson statistic has a possible range of values from 0 to 4, with the midpoint being 2 .

Hypothesis:

$\mathrm{H}_{0}$ : no significant correlation amongst residuals.

\begin{tabular}{|c|c|c|c|c|}
\hline \multicolumn{5}{|c|}{ Regions of Acceptance and Rejection of the Null Hypothesis } \\
\hline Zero to $d_{1}$ & $\mathrm{~d}_{1}$ to $\mathrm{d}_{\mathrm{u}}$ & $\mathrm{d}_{\mathrm{u}}$ to $\left(4-\mathrm{d}_{\mathrm{u}}\right)$ & $\left(4-d_{u}\right)$ to $\left(4-d_{1}\right)$ & $\left(4-d_{1}\right)$ to 4 \\
\hline Zero to 1.57 & 1.57 to 1.78 & 1.78 to 2.22 & 2.22 to 2.43 & 2.43 to 4 \\
\hline $\begin{array}{c}\text { Reject Null } \\
\text { Ho : Positive } \\
\text { Autocorrelation }\end{array}$ & $\begin{array}{c}\text { Neither accept } \\
\text { or reject }\end{array}$ & $\begin{array}{c}\text { Accept the Null } \\
\text { Hypotheis }\end{array}$ & $\begin{array}{c}\text { Neither accept } \\
\text { or reject }\end{array}$ & $\begin{array}{l}\text { Reject Null Ho: } \\
\text { Negative } \\
\text { Autocorrelation }\end{array}$ \\
\hline
\end{tabular}

\begin{tabular}{|c|c|c|c|c|c|c|c|c|c|c|}
\hline \multicolumn{10}{|c|}{ Significance Points of $\mathrm{d}_{1}$ and $\mathrm{d}_{\mathrm{u}}$ at $5 \%$} \\
\hline \multirow{2}{*}{$\mathrm{n}$} & \multicolumn{2}{|c|}{$\mathrm{k}=1$} & \multicolumn{2}{c|}{$\mathrm{k}=2$} & \multicolumn{2}{c|}{$\mathrm{k}=3$} & \multicolumn{2}{c|}{$\mathrm{k}=4$} & \multicolumn{2}{c|}{$\mathrm{k}=5$} \\
\cline { 2 - 12 } & $\mathrm{d}_{1}$ & $\mathrm{~d}_{\mathrm{u}}$ & $\mathrm{d}_{1}$ & $\mathrm{~d}_{\mathrm{u}}$ & $\mathrm{d}_{1}$ & $\mathrm{~d}_{\mathrm{u}}$ & $\mathrm{d}_{1}$ & $\mathrm{~d}_{\mathrm{u}}$ & $\mathrm{d}_{1}$ & $\mathrm{~d}_{\mathrm{u}}$ \\
\hline 50 & 1.50 & 1.59 & 1.46 & 1.63 & 1.42 & 1.67 & 1.38 & 1.72 & 1.34 & 1.77 \\
\hline 60 & 1.55 & 1.62 & 1.51 & 1.65 & 1.48 & 1.69 & 1.44 & 1.73 & 1.41 & 1.77 \\
\hline 70 & 1.58 & 1.64 & 1.55 & 1.67 & 1.52 & 1.70 & 1.49 & 1.74 & 1.46 & 1.77 \\
\hline 80 & 1.61 & 1.66 & 1.59 & 1.69 & 1.56 & 1.72 & 1.53 & 1.74 & 1.51 & 1.77 \\
\hline 90 & 1.63 & 1.68 & 1.61 & 1.70 & 1.59 & 1.73 & 1.57 & 1.75 & 1.54 & 1.78 \\
\hline $100+$ & 1.65 & 1.69 & 1.63 & 1.72 & 1.61 & 1.74 & 1.59 & 1.76 & 1.57 & 1.78 \\
\hline
\end{tabular}

Where: $\mathrm{k}=$ the number of independent variables in the equation. 
Appendix 2 - Chow Test Description

The Chow Test is given by the following equation:

$F=\frac{\left(E S S_{R}-E S S_{1}-E S S_{2}\right) / k}{\left(E S S_{1}+E S S_{2}\right) /(n-2 k)}$

Where:

$k=$ The number of regression coefficients in the model

$n=$ The number of observations in the pooled model

$E S S_{1}=$ The error sum of squared residuals for the first group

$E S S_{2}=$ The error sum of squared residuals for the second group

$E S S_{R}=$ The error sum of squared residuals for the pooled sample

$\mathrm{H}_{0}=$ No structural change in the model

$\mathrm{H}_{\mathrm{a}}=$ There is structural change in the model

If the calculate $\mathrm{F}$ statistic $>\mathrm{F}_{\mathrm{k}, \mathrm{n}-2 \mathrm{k}}$ (from the $\mathrm{F}$-distribution table) then we would reject the null hypothesis that there is no structural change. 